\title{
Bacterial cytochrome P450-catalyzed regio- and stereoselective steroid hydroxylation enabled by directed evolution and rational design
}

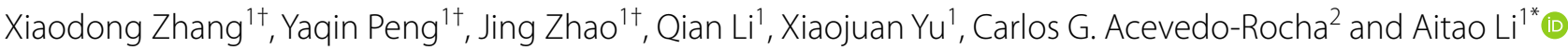

\begin{abstract}
Steroids are the most widely marketed products by the pharmaceutical industry after antibiotics. Steroid hydroxylation is one of the most important functionalizations because their derivatives enable a higher biological activity compared to their less polar non-hydroxylated analogs. Bacterial cytochrome P450s constitute promising biocatalysts for steroid hydroxylation due to their high expression level in common workhorses like Escherichia coli. However, they often suffer from wrong or insufficient regio- and/or stereoselectivity, low activity, narrow substrate range as well as insufficient thermostability, which hampers their industrial application. Fortunately, these problems can be generally solved by protein engineering based on directed evolution and rational design. In this work, an overview of recent developments on the engineering of bacterial cytochrome P450s for steroid hydroxylation is presented.
\end{abstract}

Keywords: Biocatalysis, Cytochrome P450, Steroid hydroxylation, Regioselectivity, Stereoselectivity, Directed evolution, Rational design

\section{Introduction}

Cytochrome P450 (CYPs) belong to a superfamily of heme-containing enzymes which typically act as monooxygenase, catalyzing the reductive scission of molecular oxygen, thereby introducing one oxygen atom into the substrate, whereas the second oxygen atom is reduced to water (Urlacher and Girhard 2012). To achieve high catalytic activity, CYPs must be associated with redox partner proteins which can transfer electrons from $\mathrm{NAD}(\mathrm{P}) \mathrm{H}$ via flavins (FMN, FAD) or Fe-S clusters

\footnotetext{
*Correspondence: aitaoli@hubu.edu.cn

${ }^{+}$Xiaodong Zhang, Yaqin Peng and Jing Zhao contributed equally to this work

1 State Key Laboratory of Biocatalysis and Enzyme Engineering, Hubei Collaborative Innovation Center for Green Transformation of Bio-Resources, Hubei Key Laboratory of Industrial Biotechnology, School of Life Sciences, Hubei University, Wuhan 430062, People's Republic of China

Full list of author information is available at the end of the article
}

to the P450 heme center. Based on the different electron transport types, P450s can be classified into three-, two- or one-protein systems (Fig. 1). CYPs are versatile biocatalysts and are capable of catalyzing regio- and stereoselective functionalization of non-activated hydrocarbons under mild reaction conditions (Guengerich et al. 2016), thus accomplishing chemical transformations that are of significant challenge in synthetic organic chemistry (Renault et al. 2014; Li et al. 2002). Since their discovery, CYPs have attracted researchers from different areas of science including metabolic engineering (Renault et al. 2014), synthetic biology (Girvan and Munro 2016), natural product discovery (Podust and Sherman 2012), drug metabolism (Romdhane et al. 2012; Guengerich 2001, 2008), toxicology (Behrendorff and Gillam 2016), bioremediation (Kellner et al. 1997) and plant protection (Morant et al. 2003). CYPs have also led to the generation of commercial products (Guengerich 2002). 

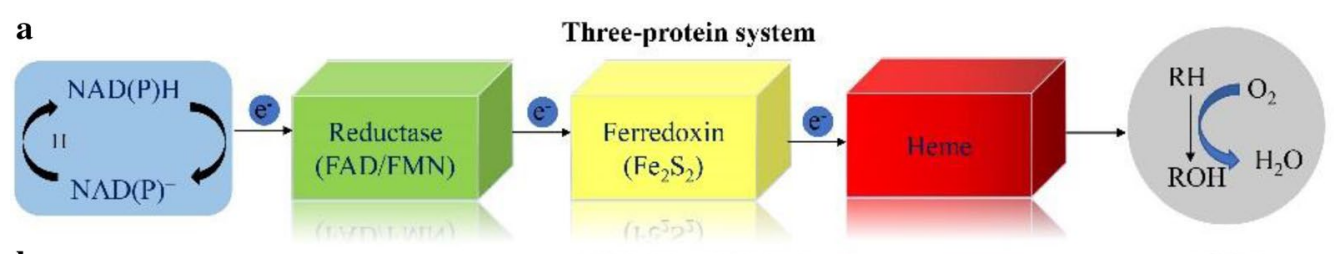

b

Two-protein system
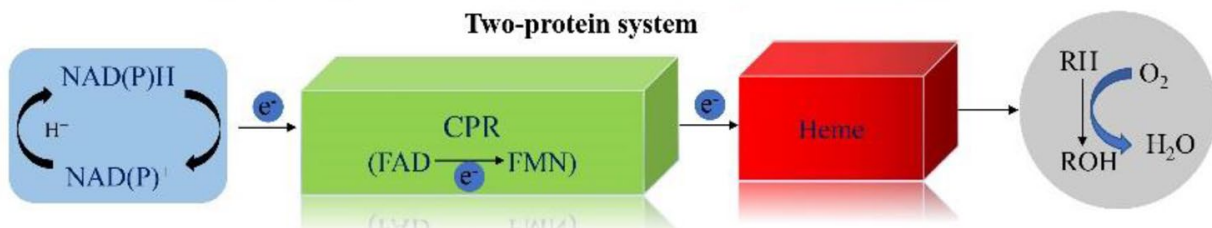

c

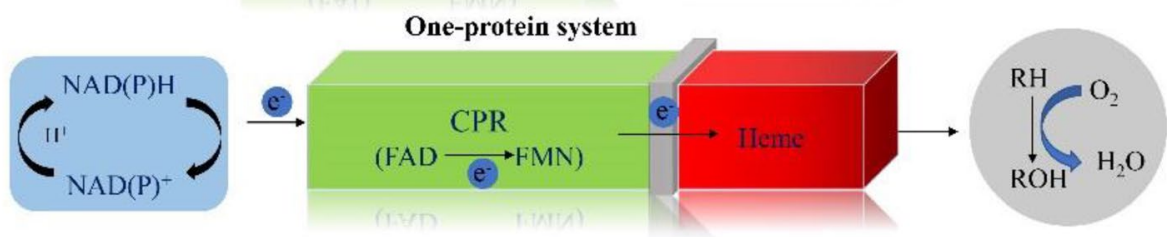

Fig. 1 Different redox systems for electron transfer in CYPs. a Three-protein systems: P450 and reductase can either be soluble or membrane-bound. b Two-protein systems: cytochrome P450 reductase (CPR) and P450 are membrane-bound. c One-protein system: soluble or membrane-bound systems formed by fusions of a CPR-like reductase and P450

As times goes on, more and more CYPs have been discovered, identified, characterized, and investigated for their ability to catalyze many types of oxidations of a vast number of substrates (Mallinson et al. 2018; O'Reilly et al. 2013; Ren et al. 2015), including, inter alia, hydroxylation (Lewis et al. 2011), epoxidation (Li et al. 2013, 2015; Guengerich 2003), sulfoxidation, dealkylation (Hartwig 2015) and $\mathrm{C}-\mathrm{C}$ bond cleavage, etc. (Bernhardt and Urlacher 2014; Munro et al. 2007; Li et al. 2016a; Coelho et al. 2013; Wang et al. 2014; Prier et al. 2017; Mallinson et al. 2018).

Steroid-based drugs are the most marketed drugs after antibiotics, of which CYP-mediated steroid hydroxylation is very important for pharmaceutical applications because this particular modification enhances their biological activity (Li et al. 2002; Fernandes et al. 2003; Donova and Egorova 2012). Current production methods of hydroxylated steroids mainly rely on fungal strains, however, bioconversion with wild-type (WT) CYPs can result in a mixture of products. For example, conversion of 11-deoxycortisol to hydrocortisone by Curvularia lunata is accompanied with an unspecific $14 \alpha$ hydroxylation (Donova 2017). On the other hand, mammalian P450s exhibit high regio- and stereoselectivity, but their activity is extremely low. For these reasons, alternative sources of CYPs are needed.

So far, a number of CYPs involved in steroid biosynthesis from different origins (plants, animals and microorganisms) have been identified using bioinformatics (Nelson 2018). Compared to eukaryotic ones, bacterial P450s possess many advantages. They can be overexpressed in high amounts in soluble form and thus are convenient for genetic diversification and purification (Bernhardt and Urlacher 2014). Moreover, bacterial CYPs are generally much more active than eukaryotic ones; typically, turnover numbers go from ten to a few hundred molecules per min. Due to the above reasons, CYPs from different bacterial species capable of hydroxylating steroids with different regioand stereoselectivity have been documented (Fig. 2). A multiple sequence alignment of corresponding steroid-hydroxylating CYPs (Gotoh 1992) showed that the substrate recognition sites (SRS) and some conserved motifs (heme binding, substrate binding, redox partner binding, proton delivery and active center) could display general features of bacterial P450s (Fig. 3). However, such bacterial WT enzymes often suffer from wrong regioselectivity, low activity, narrow substrate range and insufficient thermostability, thus restricting their industrial application. Fortunately, these problems can be generally solved with directed evolution, perhaps the most versatile tool in protein engineering, which consists of iterative rounds of gene mutagenesis, expression and screening or selection. There are two main approaches classified as random (or whole gene) and focused (or structure-based), with error-prone PCR (epPCR), DNA shuffling or recombination and saturation mutagenesis (SM) being the 3 most common methods (Qu et al. 2019). Especially structure-guided 


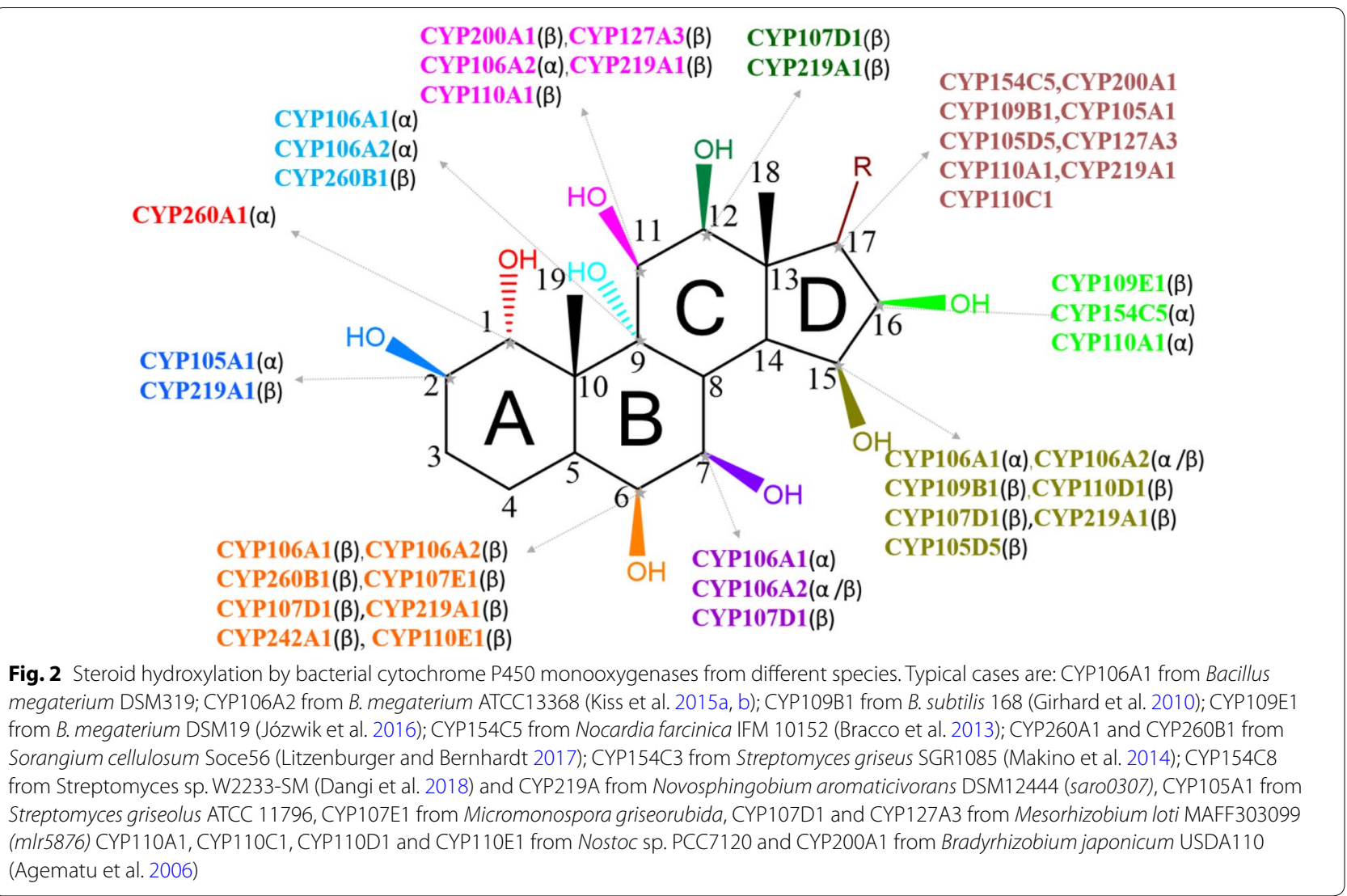

iterative SM has emerged as the optimal choice for evolving selective enzymes needed in the asymmetric synthesis of chiral intermediates and biologically active compounds (Reetz 2004, 2011; Reetz and Carballeira 2007, Reetz and Krebs 2011). Directed evolution has been successfully applied to improve both activity and selectivity of CYPs, for catalyzing not only natural reactions based on focused (Roiban and Reetz 2014) and random (Behrendorff et al. 2015; Kumar and Halpert 2005) approaches, but also non-native reactions (Urlacher and Marco 2019; Zhang et al. 2019). The discovery of new P450 enzymes, their catalytic mechanism in steroid biosynthesis as well as their critical role in steroid metabolism have been extensively investigated and have been the subject of several reviews (Agematu et al. 2006; Donova 2017; Szaleniec et al. 2018). However, works focused on bacterial CYP-catalyzed steroid hydroxylation enabled by protein engineering, have not been reported. In this review, we feature available case studies using different bacterial CYPs for steroid hydroxylation (Table 1), which is discussed according to their phylogenetic classification. Our aim is to understand the activity and selectivity profiles exhibited by WT and engineered CYPs, while exploring their potential for the development of industrial bioproces ses.

\section{CYP102A 1: cytochrome $\mathrm{P}^{450_{\mathrm{BM}}}$ from Bacillus megaterium}

CYP102A1 is a fatty acid hydroxylase that can hydroxylate $\mathrm{C} 12-\mathrm{C} 20$ fatty acids as natural substrates, and it is considered as the most active P450 thus far identified (Whitehouse et al. 2008; Narhi and Fulco 1986). Its turnover number for the native fatty acid substrates (C14-C16 is preferred) is about 3000 per min, while most CYPs show 1-300 per min (Bernhardt and Urlacher 2014). It is a single-polypeptide composed of a fusion of the heme domain and NADPH-dependent FMN/FAD reductase. The reductase domain containing two flavin and one NADPH binding region is $65 \mathrm{kDa}$, whereas the heme domain is $55 \mathrm{kDa}$, making a large protein of about 120 $\mathrm{kDa}$ (Saab-Rincon et al. 2017). Although BM3 is one of the most active CYPs, the application of the WT enzyme is limited by the fact that turnovers involving non-natural substrates often have low NADPH consumption rates and poor coupling efficiency (Whitehouse et al. 2009). Since WT BM3 does not accept bulky steroidal substrates, active-site mutagenesis needs to be implemented (Li et al. 2016b, 2017; Zhou et al. 2019). 


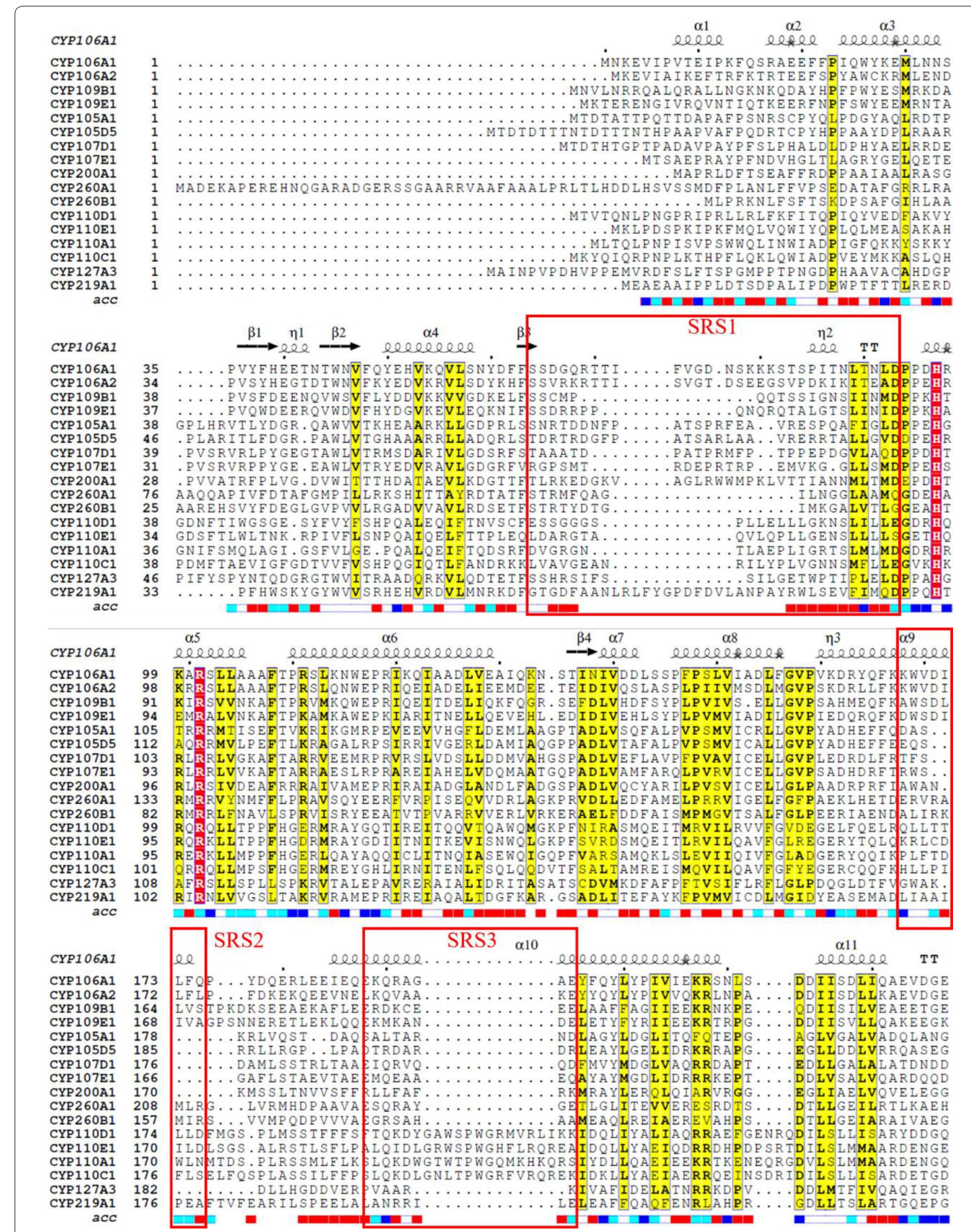

Fig. 3 Multiple sequence alignment of bacterial steroid-hydroxylating CYPs. Substrate recognition sites (SRS) and conservative motifs of bacterial P450s are enclosed in red box and black box, respectively. Conserved and similar residues are highlighted in red and yellow, respectively 


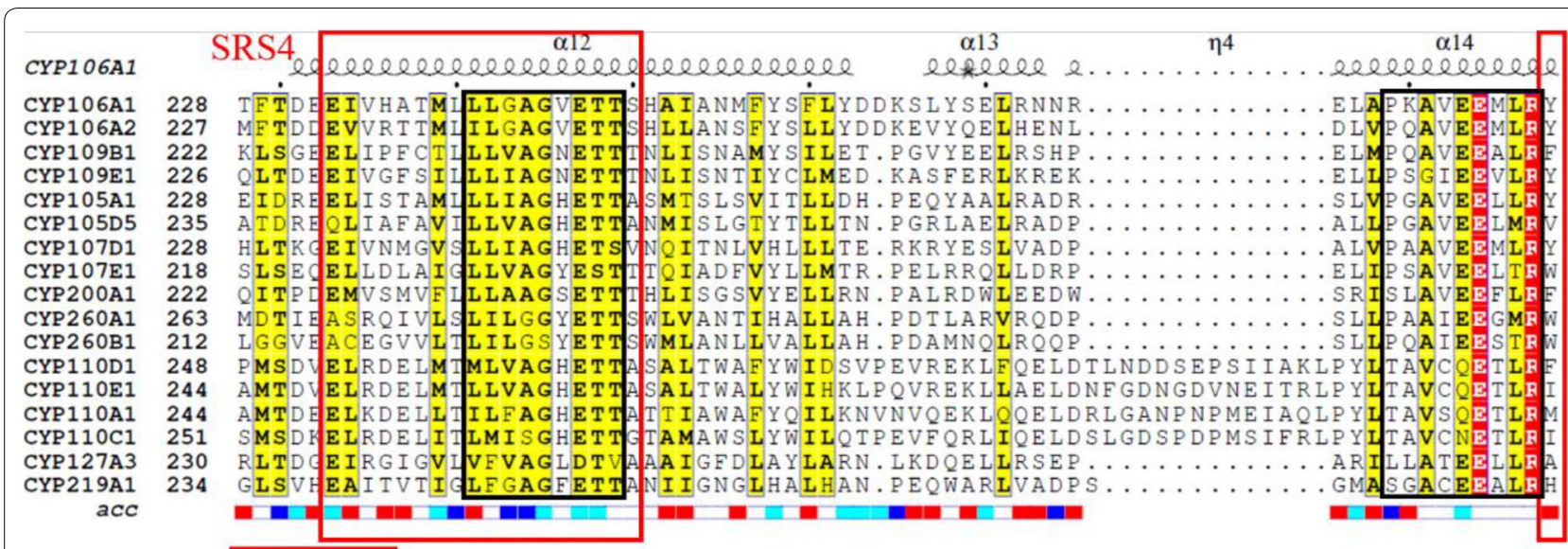

CYP106A1

CYP106A1

CYP106A2

CYP109B1

CYP105A1

CYP105D5

CYP107D1

CYP107E1

CYP 200A1

CYP 260B1

CYP110D1

CYP110E1

CYP110A1

CYP110C1

CYP219A1

SRS5

T T $\stackrel{\beta 6}{\longrightarrow} \underset{15}{\longrightarrow}$ ele

т т т $\begin{gathered}\eta 5 \\ \text { ie }\end{gathered}$ т

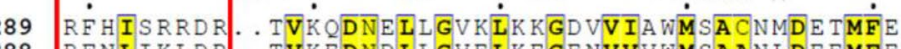

288 RFNLIKLDR. . TVKEDND L L GVELKEGENVVVWMSAAN LDEEMFE.

RAPAPVLRR. . IAKRDTEGG. HLIKEGDMVLAFVASANRDEAKFD

RSPVQALHR. . IVKEDVTLAGKKLKAGEHVVP WMGSAHRDAEYFE.

LA I AD I A G GR, VAT AD I EVEGH LIRAGE GVIVVNS I ANRDG TVYE...

LAIADIAGGR. VATADIEVEGHLIRAGEGVIVVNSIANRDGTVYE...

TPLVSAGSFVRVATEDVELSTVTVRAGEP CVVHFASANRDEEVFD...

VP L GVGTAF RYAVEDVT LRGVTIRAGEPVLASTGAANRD A A FP .

VSPVQFSKPR. YLRRDVELAGVRIKKGDRVMVMLAAANMDPAVHD.

CPSSFGVLR

C S SA A G I VR

P IVLNAFF

YP I AMV T I P
Y P VIP T L F P

NPVAMLTLP

Y P P I Q L I RV

QSSLIATYR

FVEREAT I GGETLAAGT I LYLSI I ARHYDEEIYP..... RPETFD I HRRPVGMLN

ITKTNLEIGGHQFAPGTMLVGCIYLMHRRPDLYPQPQEFRPERFLEKQYSLYEYLA

ITKSSINIAGYQLEPDTILMASIYLIHYREDLYPNPQQFRPERFIERQYSPSEYI

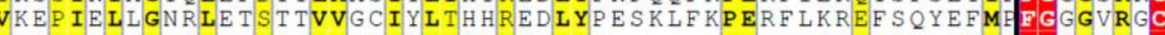

TKDIDFEGAPIRKGDYVSCATMIANRDPEEFE.

ALADTSVCGHPVSAGQRVLTLIGAANRDPRKFAD.

SPNTVDLARDHN. RHA

FGYGPRC acc

$\alpha 16$

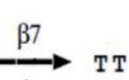

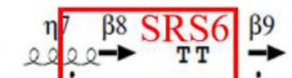

$\beta 10$

CYP106A1

CYP106A1

CYP106A2

CYP109B1

CYP109E1

CYP105A1

CYP105D5

CYP107D1

CYP107E1

CYP200A1

CYP 260A1

CYP260B1

CYP110D1

CYP110E1

CYP110A1

CYP110C1

CYP127A3

CYP219A1

acc

leeveleeleeeleel

$\overrightarrow{\mathrm{I}}$

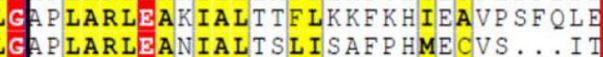

$\mathrm{L}$

作

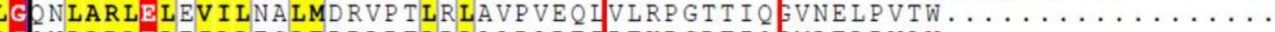

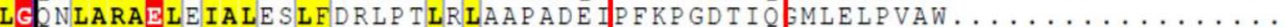

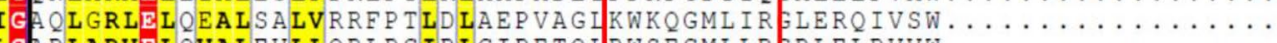
LG P LARVEL QVALEVLLQRLP G IRLGIPETQIRWSEGML L R P L E L PVVW.

LGHOLARI I A T CAL OALLARWP KLELAVDPAQIHWRKRP GMRA I ARLPVVAGGNRRP SRGAAAEPLLAD

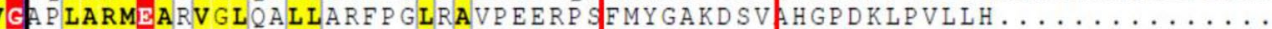

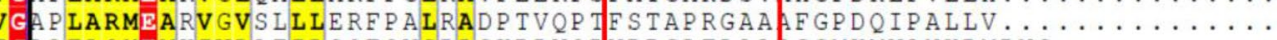

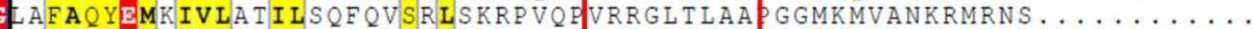

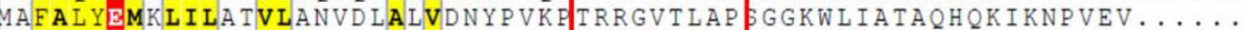

A.LALLEIKLVIATVLSNYQLALA D KPVNYQRRGFTLAP GGVRVIMTGKKSLKFEQSSKIFN. . ALAMFEMKIVLATVLSRYQLALADRKPERPQRQGETLTP FNGVKMLITGQHKRQNYSMAASTTFNA HLARREIVI GLEEWLAR I T TFRIKEGTAP ITCGGHVF G IENL I L DWS

ELARIEARVAFEHLARELPQMQVDTGGACV

RENFLFRGL

VGA ELARIEARVAFE

Fig. 3 continued

During the characterization of the substrate specificity of $\mathrm{P}^{4} 50_{\mathrm{BM} 3}$, it was reported that mutating phenylalanine at site 87 to alanine changes significantly its regiospecificity towards fatty acid hydroxylation (Oliver et al. 1997). Inspired by this finding, variant F87A was first tested for the hydroxylation of testosterone and progesterone. The mutant produces a 52:45 mixture of $2 \beta$ - and $15 \beta$-hydroxytestosterone or 18:82 mixture of
$2 \beta$ - and 16 $\beta$-hydroxyprogesterone (Kille et al. 2011). Next, the combinatorial active-site saturation test (CAST) was applied iteratively (Qu et al. 2019) on mutant F87A for improving both selectivity and activity. Twenty residues surrounding the binding pocket were divided into nine randomization sites as shown in Fig. 4. Mutagenesis was started on sites A (R47/T49/ Y51), B (V78/A82) and C (M185/L188) using NDC, 
Table 1 Summary of CYPs variants-catalyzed regio- and stereoselective steroid hydroxylation by directed evolution

\begin{tabular}{|c|c|c|c|c|}
\hline CYPs & Mutants & Results & Conversion & Protein engineering strategy \\
\hline \multirow[t]{19}{*}{ CYP102A1 (Bacillus megaterium) } & KSA-1 & 97\% 2 $\beta$-hydroxytestosterone & 79 & \multirow{4}{*}{$\begin{array}{l}\text { Directed evolution based on CAST, } \\
\text { ISM, MLs, MDs, etc. (Kille et al. 2011) }\end{array}$} \\
\hline & KSA-1 & 91\% 16ß-hydroxyprogesterone & n.d. ${ }^{*}$ & \\
\hline & KSA-9 & 100\% 2 $\beta$-hydroxyprogesterone & n.d.* & \\
\hline & KSA-14 & 94\% 15ß-hydroxytestosterone & 85 & \\
\hline & M01-A82W & $85 \%$ 16ß-hydroxytestosterone & n.d. & \multirow{5}{*}{$\begin{array}{l}\text { Rational design based on site- } \\
\text { directed mutagenesis. (Rea et al. } \\
\text { 2012; Venkataraman et al. 2012) }\end{array}$} \\
\hline & M01-A82W & 88\% 16ß-hydroxynorethisterone & n.d.* & \\
\hline & M11-A82W & 75\% 16ß-hydroxytestosterone & n.d.* & \\
\hline & M11-A82W & 78\% 16ß-hydroxynorethisterone & n.d.* & \\
\hline & M01-A82W/S721 & 81\% 16a-hydroxytestosterone & n.d.* & \\
\hline & WIFI-WC & 96\% 16ß-hydroxyprogesterone & $95 \%$ & \multirow{9}{*}{$\begin{array}{l}\text { Directed evolution based on CAST, } \\
\text { ISM, MLs, MDs, etc. (Acevedo-Rocha } \\
\text { et al. 2018) }\end{array}$} \\
\hline & WIFI-WC & 95\% 16a-hydroxyandrostenedione & $85 \%$ & \\
\hline & WWV-QRS & 92\% 16ß- hydroxyprogesterone & $92 \%$ & \\
\hline & WWV-HMQ & 100\% 16ß-hydroxyandrostenedione & $93 \%$ & \\
\hline & WWV-Q & 90\% 16ß-hydroxynandrolone & $91 \%$ & \\
\hline & WWV-Q & 72\% 16ß-hydroxyboldenone & $71 \%$ & \\
\hline & WWI & 91\% 16ß-hydroxynorethindrone & $59 \%$ & \\
\hline & LIFI-CW & 98\% 16ß-hydroxynandrolone & $71 \%$ & \\
\hline & LIFI-CW & 97\% 16ß-hydroxyboldenone & $70 \%$ & \\
\hline & $139-3$ & 100\% 1a-hydroxyandrostenedione & $37 \%$ & $\begin{array}{l}\text { Random mutagenesis. (Liu and Kong } \\
\text { 2017) }\end{array}$ \\
\hline \multirow{2}{*}{$\begin{array}{l}\text { CYP106A2 (Bacillus megaterium } \\
\text { ATCC 13368) }\end{array}$} & T89N/A395I & 81\% 11a-hydroxyprogesterone & 24.4- fold than WT & \multirow{2}{*}{$\begin{array}{l}\text { Directed evolution based on CAST, } \\
\text { ISM, MLs, MDs, etc. (Nguyen et al. } \\
\text { 2012; Nikolaus et al. 2017) }\end{array}$} \\
\hline & A243S & 88.8\% 6ß-hydroxyprogesterone & $93.1 \%$ & \\
\hline \multirow{5}{*}{$\begin{array}{l}\text { CYP260A1 (myxobacterium Soran- } \\
\text { gium cellulosum Soce56) }\end{array}$} & S276N & 57\% 1a-hydroxyprogesterone & n.d. ${ }^{*}$ & \multirow{5}{*}{$\begin{array}{l}\text { Directed evolution based on CAST, } \\
\text { ISM, MLs, MDs, etc. (Khatri et al. } \\
\text { 2018) }\end{array}$} \\
\hline & S276C & 48\% 1a-hydroxyprogesterone & n.d.* & \\
\hline & S2761 & 64\% 17a-hydroxyprogesterone & n.d.* & \\
\hline & S276L & 62\% 17a-hydroxyprogesterone & n.d.* & \\
\hline & S276V & 58\% 17a-hydroxyprogesterone & n.d.. & \\
\hline CYP260B1 (Sorangium cellulosum) & T224A & $\begin{array}{l}\text { 75\% 9a-hydroxy-11- } \\
\text { deoxycorticosterone }\end{array}$ & $100 \%$ & $\begin{array}{l}\text { Rational design based on site- } \\
\text { directed mutagenesis (Litzenburger } \\
\text { and Bernhardt 2017) }\end{array}$ \\
\hline
\end{tabular}

The detailed information of CYP102A1 mutants are as follows: KSA-1 (F87A/A330W), KSA-9 (A82N/F87A), KSA-14 (R47Y/T49F/V78L/A82M/F87A), M01-A82W (R47L/ F87V/L188Q/E267V/G415S/A82W), M11-A82W (R47L/F87V/L188Q/E267V/G415S/E64G/F81I/E143G/A82W), M01-A82W/S72I (R47L/F87V/L188Q/E267V/G415S/A82W/ S72I), WIFI-WC (R47W/S72I/A82F/S72I/Y51W/L181C), WWV-QRS (R47W/A82W/F87V-L181Q/T436R/M177S), WWV-HQM (R47W/A82W/F87V/Y51H/L181Q), WWV-Q (R47W/A82W/F87V/L181Q), WWI (R47W/A82W/F87I), LIFI-CW (R47L/S72I/A82F/F87I/L188C/A330W) 139-3 (V78A/H138Y/T175I/V178I/A184V/H36Q/E252G/R255S/ A290V/A295T/L353V)

NNK and NDC mutagenesis, respectively. Degenerate codon NNK codes for 20 amino acids, while NDC codes for a set of 12 amino acids whose side-chains include polar/nonpolar, charged/uncharged and aromatic/nonaromatic substitutions. After a considerable screening effort of three libraries, mutants showing very high regio- and stereoselectivity were obtained. For example, for testosterone hydroxylation, mutant KSA-1 (F87A/A330W) and KSA-14 (R47Y/T49F/ $\mathrm{V} 78 \mathrm{~L} / \mathrm{A} 82 \mathrm{M} / \mathrm{F} 87 \mathrm{~A})$ show $97 \% 2 \beta$-selectivity and $94 \%$ $15 \beta$-selectivity, respectively (Fig. $5 \mathrm{a}$ ). In the case of progesterone, mutant KSA-9 (A82N/F87A) exhibited 100\% $2 \beta$-selectivity, whereas mutant KSA-1 (F87A/A330W) displayed 91\% 16ß-selectivity (Fig. 5b).
In summary, this directed evolution strategy demonstrated how iterative saturation mutagenesis (ISM) enabled the hydroxylation of two steroids with high regio- and stereoselectivity. However, the screening effort was extremely high. About 9000 mutants were screened in order to obtain two selective mutants for each substrate, which represented a screening effort of about 18,000 colonies in a rather low-throughput screening assay. In addition, the activity of mutants towards progesterone is very low. Thus, methodology development was needed to make directed evolution faster and more reliable.

To the best of our knowledge, the first reported engineered P450 for steroid hydroxylation was the triple 


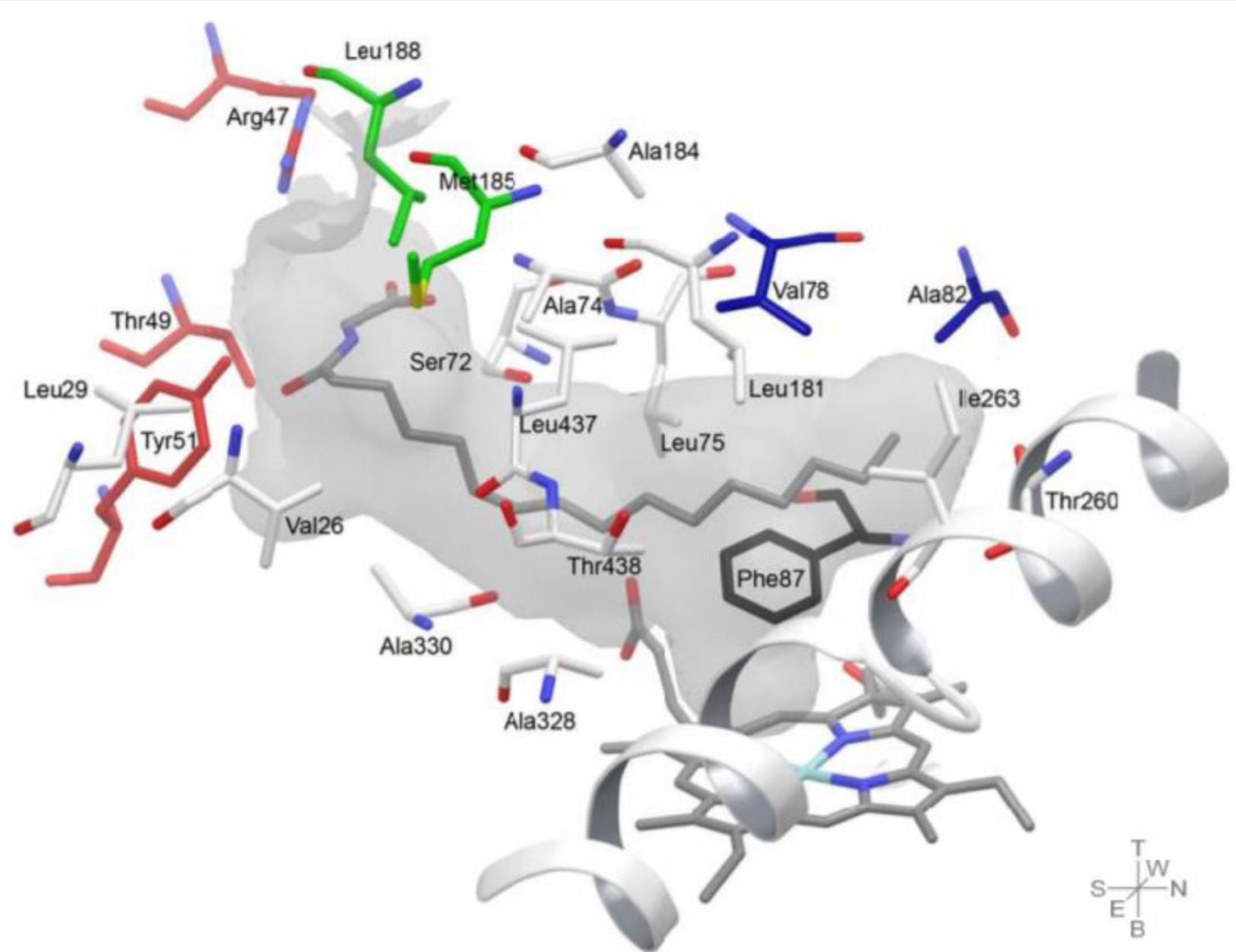

Fig. 4 Active-site residues in the X-ray crystal structure of the N-palmitoylglycine (NPG)-bound form of the heme domain of wild-type $P 450_{B M 3}$ (1 JPZ). The nine sites are labeled as a (R47/T49/Y51), b (V78/A82), c (M185/L188), d (S72/A74/L75), e (L181/A184), f (T260/I263), g (A328/A330), h $(\llcorner 437, T 438)$ and $\mathbf{i}(V 26, L 29)$. The mutant F87A is served as the starting template (Kille et al. 2011)

mutant R47L/L188Q/F87V. It was generated by combining three different mutations via site-directed mutagenesis based on the 3D structure. Earlier, this mutant was engineered by rational design for the oxidation of various substrates (Lussenburg et al. 2005), but it also showed activity on various steroids (testosterone, progesterone, androstenedione and nandrolone), yielding different monohydroxylated metabolites that were not identified (van Vugt-Lussenburg et al. 2006). Later on, the triple mutant was subjected to random mutagenesis, generating variants M01 (R47L/F87V/L188Q/E267V/G415S) and M11 (M01 plus mutations E64G/F81I/E143G) that exhibited increased steroid metabolizing activity. Both variants were tested for their capacity to catalyze the transformation of testosterone and norethisterone, resulting in three and two monohydroxylated products, but with rather low activity and selectivity (de Vlieger et al. 2010; Vottero et al. 2011). It was previously shown that increasing the size and hydrophobicity of active-site residue at position 82 by mutations $\mathrm{A} 82 \mathrm{~F}$ and $\mathrm{A} 82 \mathrm{~W}$ in WT P450 $0_{\mathrm{BM} 3}$ strongly improves binding affinity for fatty acids and indoles, thus leading to substantially increased catalytic efficiency (Huang et al. 2007). Therefore, Commandeur et al. investigated whether the introduction of the A $82 \mathrm{~W}$ mutation into $\mathrm{P} 50_{\mathrm{BM} 3}$ mutants M01 and M11 would affect the activity and/or regioselectivity of steroid hydroxylation (Rea et al. 2012). As expected, mutants M01-A82W and M11-A82W switched selectivity from $15 \beta$ to $16 \beta$ for both testosterone and norethisterone. For testosterone, the selectivity for $16 \beta$-hydroxytestosterone increased starkly from 22 to $85 \%$ and 25 to $75 \%$ by mutants M01-A82W and M11-A82W, respectively. In both cases, major products $15 \beta$-hydroxytestosterone and $2 \beta$-hydroxytestosterone were substantially reduced. In the case of norethisterone, similar results were achieved with 16ß-hydroxynorethisterone, selectivity increasing from 42 to $88 \%$ and from 58 to $78 \%$ with the same mutants, respectively.

Subsequently, Commandeur's group reported that a single active-site mutation at position S72 of variant M01-A82W shifts stereoselectivity of testosterone hydroxylation from $16 \beta$ to $16 \alpha$ (Venkataraman et al. 2012). Mutation S72V in M01-A $82 \mathrm{~W}$ led to formation of ca. $20 \%$ of $16 \alpha$-hydroxytestosterone, but with $40 \%$ $16 \beta$-hydroxytestosterone still being the major product (Fig. 6). Nevertheless, the authors successfully improved 

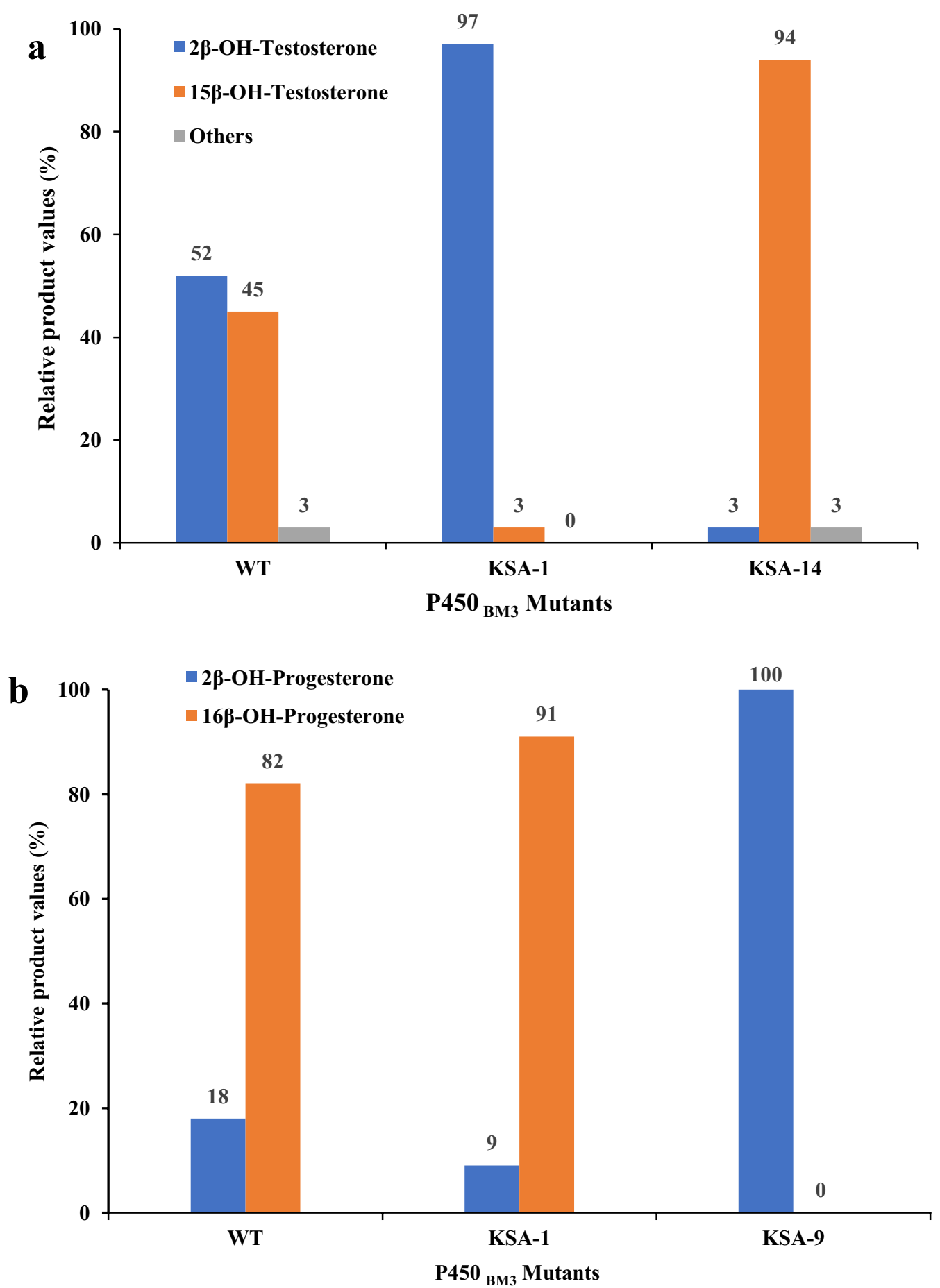

Fig. 5 Relative amounts of hydroxylated products of testosterone (a) catalyzed by P450 $_{\text {BM3 }}$ and its mutants KSA-1 (F87A/A330W) and KSA-9 (A82N/F87A); and hydroxylated products of progesterone (b) catalyzed by P450 ${ }_{\text {BM }}$ and its mutants KSA-1 (F87A/A330W) and KSA-14 (A82N/F87A),

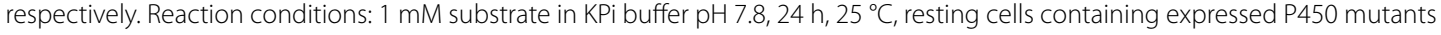

the formation of $16 \alpha$-hydroxytestosterone with $81 \%$ selectivity and only $5 \%$ of $16 \beta$-hydroxytestosterone as minor product by introducing mutation S72I into
M01-A82W. However, the activity of the mutant reduced by $2-3$ times.

With the three P450 ${ }_{\mathrm{BM} 3}$ mutants (M01-A82W, M11A82W and M01-A82W/S72I) in hand, Kong et al. probed 

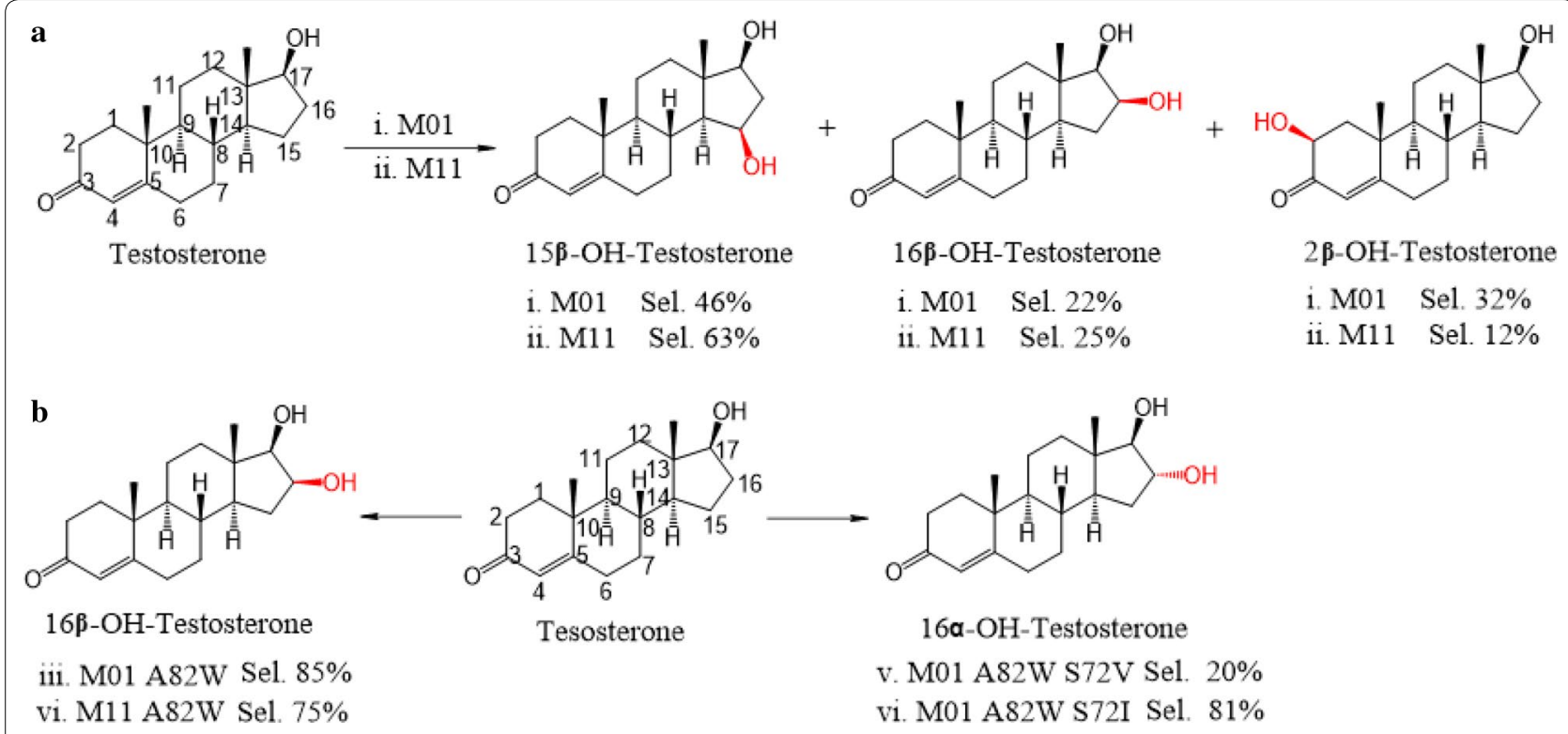

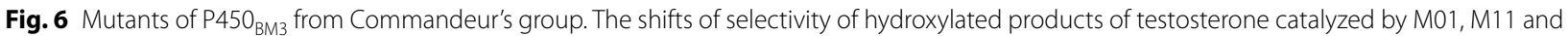
their mutants M01-A82W, M11-A82W, M01-A82W/S72V. The major hydroxylated products of testosterone by M01 and M11 are shown in a and by their mutants are showed in $\mathbf{b}$. Reaction conditions: $500 \mathrm{nM}$ purified enzymes containing $0.5 \mathrm{mM}$ testosterone in $250 \mu \mathrm{L} 100 \mathrm{mM} \mathrm{KPi} \mathrm{buffer} \mathrm{pH} \mathrm{7.4,}$ $25 \mathrm{\mu L}$ NADPH regeneration system containing 2 mM NADPH, 3 mM glucose-6-phosphate and $4 \mathrm{U} / \mathrm{mL}$ of glucose-6-phosphate dehydrogenase, 1 h, $24^{\circ} \mathrm{C}$

the steroidal substrate diversity of these variants with various steroid precursors (Liu et al. 2016). Eight steroids including two 3 -keto- $\Delta^{4}$-steroids (testosterone and methyltestosterone) and six 3-hydroxy-5-steroids (cholesterol, $\beta$-sitosterol, dehydroepiandrosterone, diosgenin, pregnenolone and ergosterol) were tested. It was found that the three mutants exhibited activity only towards the two 3-keto- $\Delta^{4}$-steroids, but not on the remaining six 3 -hydroxy- $\Delta^{5}$-steroids.

The aforementioned mutants derived from M01 and M11 display high regio- and stereoselectivity, but low catalytic activity for steroids at position C16. To improve the activity and selectivity simultaneously, it is crucial to solve the issues of diminishing returns and trade-offs in protein engineering (Tokuriki et al. 2012). Moreover, a general problem with the M01-derived mutants is that they are unstable due to disruption of salt bridges and hydrophobic contacts (Geronimo et al. 2016), thus limiting their industrial applications.

Recently, Reetz et al. developed an efficient directed evolution strategy under the guidance of mutability landscape construction to control P450-catalyzed steroid hydroxylation at position 16 with high regio-and diastereoselectivity (Acevedo-Rocha et al. 2018). The authors developed a combined approach concerning the information obtained from mutability landscapes (MLs) and molecular dynamics simulation (MDs) to perform rational iterative saturation mutagenesis (ISM) to escape from diminishing returns and trade-offs with a relatively low screening effort (Fig. 7a). With this approach, two excellent mutants WIFI-WC (R47W/S72I/A82F/ S72I-Y51W/L181C) and WWV-QRS (R47W/A82W/ F87V-L181Q/T436R/M177S) allowed testosterone hydroxylation at positions $16 \alpha$ and $16 \beta$ with both activity and selectivity above $92 \%$ (Fig. 7b). Compared with M01 and M11-derived variants, the mutants generated in this study greatly improved activity and selectivity. In addition, other steroids (androstenedione, nandrolone, boldenone, and norethindrone) were also activated at position C16 with excellent activity and diastereoselectivity. Overall, the screening effort was about 3000 samples for five different substrates, each with two hydroxylated products. Thus, this combined approach was promising to be an effective method in the directed evolution of other enzymes. More importantly, the functionalization of steroids at position 16 with hydroxyl groups is relevant to develop glucocorticoids for the pharmaceutical industry.

Another study about steroid hydroxylation using $\mathrm{P}^{4} 50_{\mathrm{BM} 3}$ was reported but using this time variant 139-3 (containing 11 amino substitutions), which was generated in five generations of random mutagenesis with small alkanes as targeted substrates (Glieder et al. 2002). The $\mathrm{P}^{4} 50_{\mathrm{BM}}$ variant $139-3$ was used to screen 13 steroid substrates, but it was only able to specifically hydroxylate androstenedione at position $1 \alpha$ with a maximum substrate conversion of 37\% (Liu and Kong 2017). Random 
$\mathbf{a}$

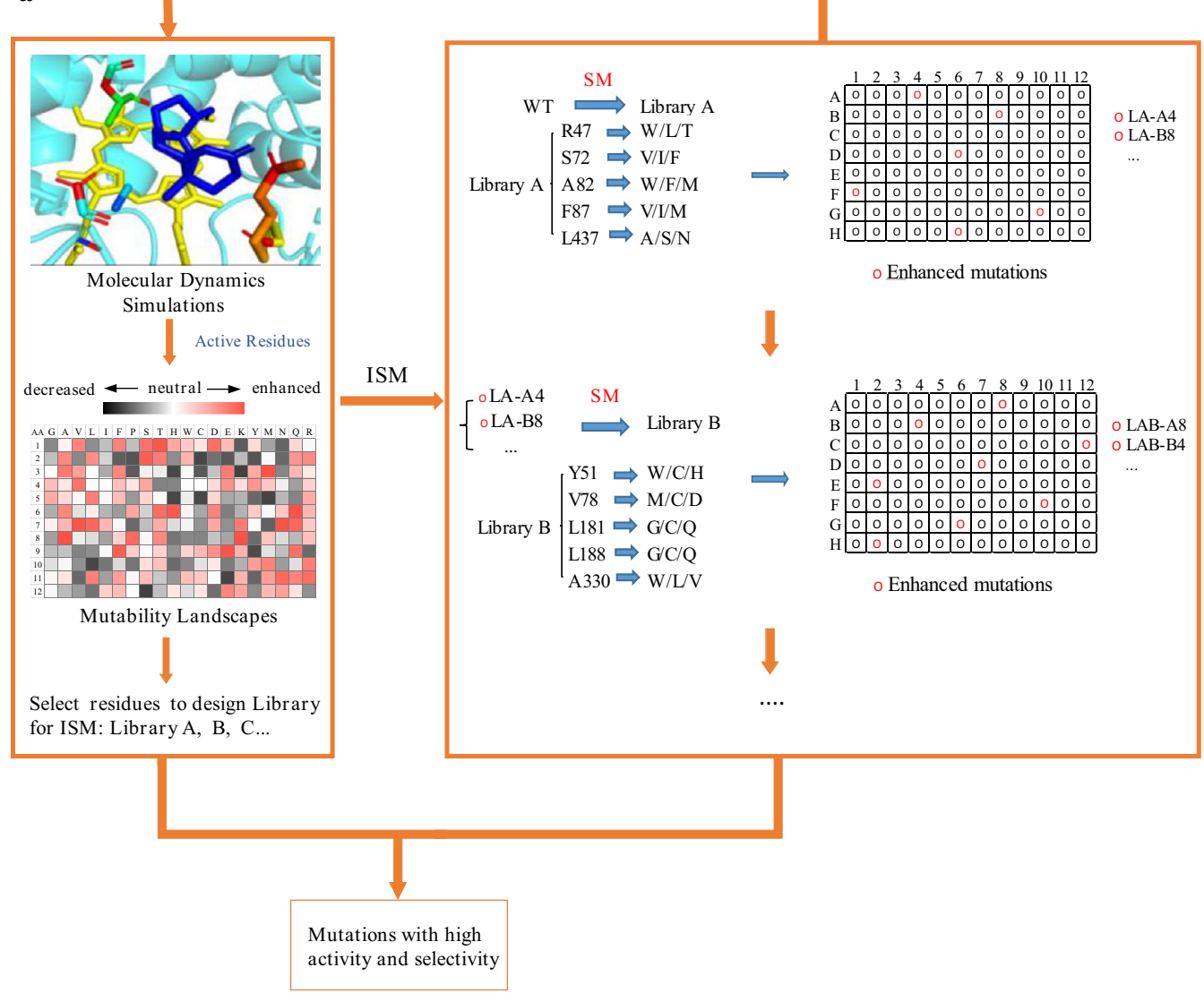

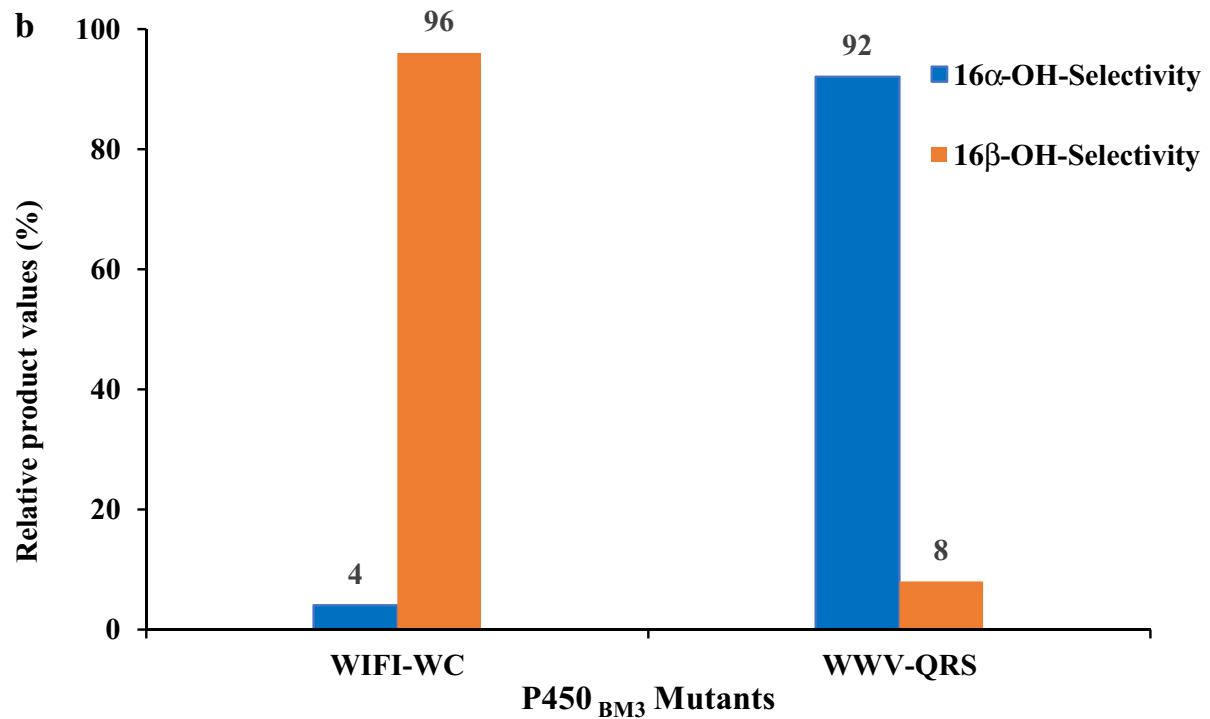

Fig. 7 Controlling regio- and diastereoselectivity at position 16 of various steroids. a The directed evolution strategy of $\mathrm{P}_{450_{B M 3}}$ : mutability landscapes (MLs), molecular dynamics simulation (MDS) and iterative saturation mutagenesis (ISM) are combined to design the mutations. $\mathbf{b}$ Conversion and selectivity of hydroxylated products of testosterone catalyzed by the best two P450 BM3 mutants WIFI-WC (R47W/S72I/A82F/ S72I-Y51W/L181C) and WWV-QRS (R47W/A82W/F87V-L181Q/T436R/M177S), respectively. Reaction conditions: $1 \mathrm{mM}$ testosterone in 600 $\mu \mathrm{L}$, $100 \mathrm{mM} \mathrm{KPi}$ buffer $\mathrm{pH} 8.0$ for $24 \mathrm{~h}, 220 \mathrm{rpm}, 37^{\circ} \mathrm{C}$ 
mutagenesis based on epPCR was performed aiming to further improve activity and substrates specificity of variant 139-3 without a clear target position or type of functionalization, but no improved variants were found. Mutation R379S caused a complete loss of the hydroxylation activity for androstenedione, demonstrating the importance of arginine 379 for enabling $1 \alpha$-hydroxylated activity of 139-3.

\section{CYP106A2: steroid-specific P450 from Bacillus megaterium ATCC 13,368}

This bacterial class I enzyme is one of a few tested soluble steroid hydroxylases, which was also identified as a regio- and stereoselective $15 \beta$-hydroxylase of 3 -oxo- $\Delta^{4}$ -steroids (Berg et al. 1976, 1979; Schmitz et al. 2018). Furthermore, CYP106A2 is a potent hydroxylase of 3-hydroxy- $\Delta^{5}$-steroids, di- and triterpenoid, although its natural substrate and biological function are not clarified yet (Bleif et al. 2011, 2012; Schmitz et al. 2012; Kiss et al. 2015a, b). Recently, it was found that CYP106A2 is not strictly $15 \beta$-selective to progesterone, as positions $6 \beta, 9 \alpha$ and $11 \alpha$ have also been observed as targets for hydroxylation particularly when adrenodoxin (Adx) and adrenodoxin reductase (AdR) or putidaredoxin reductase (PdR) and putidaredoxin (Pdx) served as redox systems (Fig. 8) (Lisurek et al. 2004, 2008; Nguyen et al. 2012; Virus et al. 2006).

Engineered E. coli or B. subtilis cells expressing CYP106A2 have been employed as biocatalysts for industrial biotransformations (Rauschenbach et al. 1993). In recent decades, the substrate spectrum of CYP106A2 has been largely expanded, demonstrating its excellent application in the pharmaceutical industry (Lisurek et al. 2004). Moreover, electron supply of CYP106A2 could be achieved with various redox systems, though its natural electron partners have never been identified (Ringle et al. 2013; Hannemann and Bernhardt 2006; Bleif et al. 2012; Schmitz et al. 2012). To further exploit the potential of this CYP, both rational mutagenesis and CAST have been applied to change the regio- and stereoselectivity towards steroid hydroxylation (Bernhardt 2008).

The structure of CYP106A2 was not clear until 2008, but a structural model has been built based on CYP11B1 by applying computational tools. With this information, a series of active-site mutants were created and screened for the improvement of steroid-hydroxylating activity (Lisurek et al. 2008). Mutants S394I, A395L, T396, G397P and Q398S exhibited decreased activity, especially for those mutants with mutations at the substrate recognition sites (A395, T396, G397). In terms of the selectivity and compared to the WT enzyme, mutant A395L showed 4- and 5-fold improvement for $11 \alpha$ - and $9 \alpha$-hydroxylation of progesterone, respectively. Mutant G397P also showed more than four and twofold increase in the relative formation of $11 \alpha$-hydroxyprogesterone and $6 \alpha$-hydroxyprogesterone (Lisurek et al. 2008).

Subsequently, based on the homology model of CYP106A2 with the progesterone docked in the binding pocket, a CAST library at amino acid positions A395 and G397 lining in the binding pocket was created with the aim of switching the selectivity from C15 to $\mathrm{C} 11$ in progesterone hydroxylation (Nguyen et al.

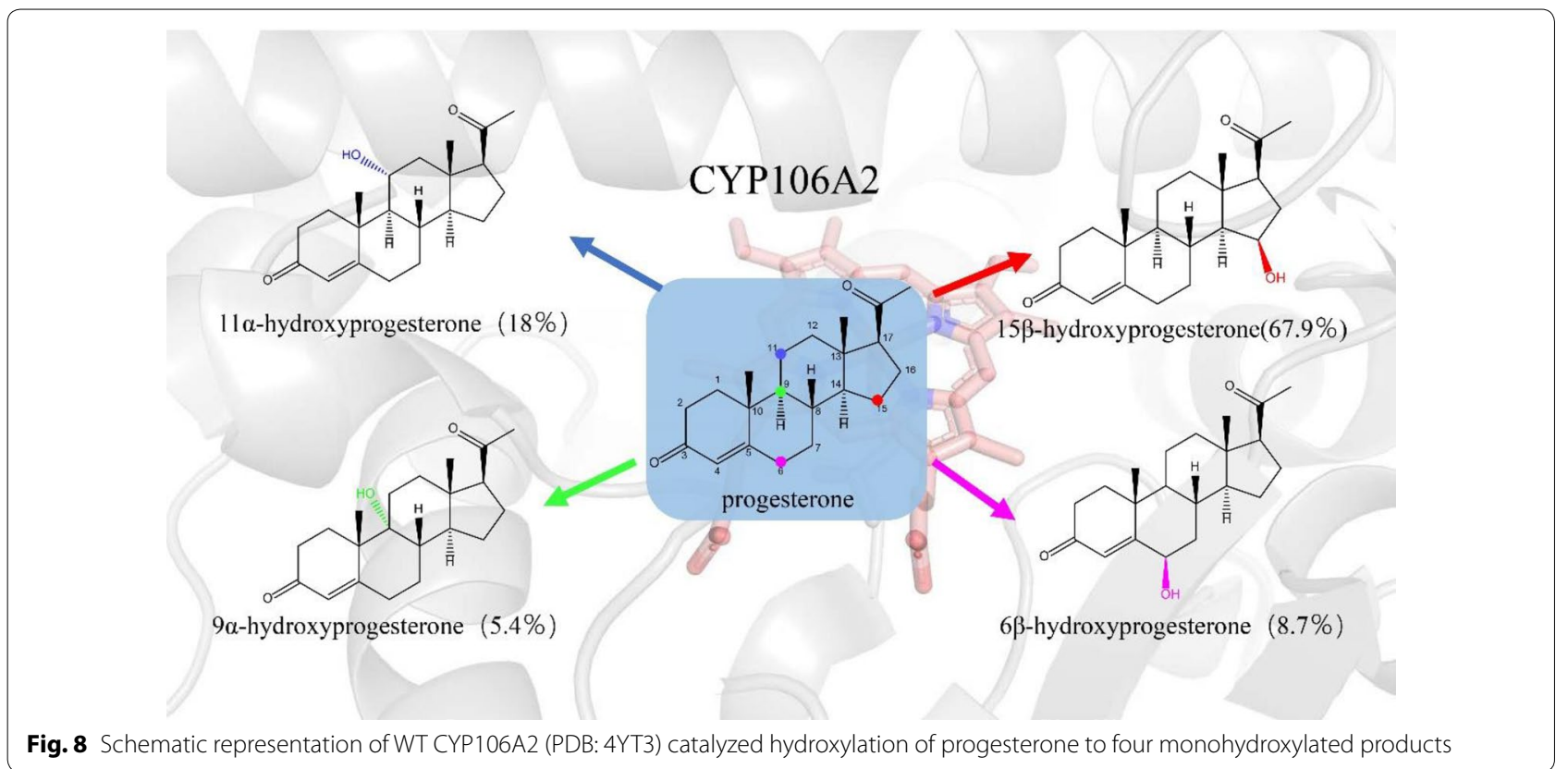


2012). After screening the SM library, two mutants A395I and A395W/G397K were obtained with 8.9- and 11.5 -fold enhancement for $11 \alpha$-hydroxylase activity, respectively. To further increase catalytic efficiency, rational site-directed mutagenesis was undertaken to generate mutants A106T/A395I, A106T/A395I/R409L and T89N/A395I, which led to increased $11 \alpha$-selectivity and activities relative to the WT (enhancements of 14, 13-, and 12-fold selectivity and 39, 108, and 24-fold $K_{c a t} / k_{m}$ ) (Nguyen et al. 2012). The best mutant T89N/ A395I was then employed in a whole-cell biotransformation with progesterone, indicating that the formation of $11 \alpha$-hydroxyprogesterone increased from 28 to $81 \%$, while 15 $\beta$-hydroxyprogesterone decreased from 50.4 (WT) to 4.8\% (Nguyen et al. 2012) (Fig. 9).

In 2016, CYP106A2 was crystallized and the 3D structure was solved (Janocha et al. 2016). With the structural information in hand, Nikolaus et al. tried to improve its $9 \alpha$-hydroxylase and $6 \beta$-hydroxylase selectivity as well as activity (Nikolaus et al. 2017). Site-saturation mutagenesis was performed by targeting A395 and G397 to create a small library using CAST. Upon screening more than 13,000 clones with progesterone as model substrate, 16 mutants were obtained with improved $9 \alpha$ - and $6 \beta$-hydroxylase activity, and four of them exerted hydroxylation mainly at position $C 9 \alpha$. To improve the variants, additional mutagenesis was performed and resulting mutant F165L/A395E/G397V exhibited 11-fold increase in selectivity towards progesterone $9 \alpha$-hydroxylation. Meanwhile, mutant A243S was also discovered with improved selectivity towards 6 $\beta$-hydroxyprogesterone from 9 to 86\% (Nikolaus et al. 2017) (Table 2). Doubtless, CYP106A2 has been engineered with success using both rational design and directed evolution for some hydroxylation of pharmaceutical interest, which include positions $7 \alpha, 9 \alpha, 11 \alpha, 11 \beta, 16 \alpha$ and $17 \alpha$, among others (Donova and Egorova 2012).

\section{CYP260A1: cytochrome P450 from myxobacterium Sorangium cellulosum Soce56}

This enzyme was identified as a new class of bacterial P450 (Ewen et al. 2009; Khatri et al. 2016a) with a steroid hydroxylase activity towards C19 (testosterone and androstenedione) or C21 (11-deoxycorticosterone) type steroids at the very unique $1 \alpha$-position in the presence of surrogate redox partners (adrenodoxin and adrenodoxin reductase) (Khatri et al. 2016b; Ewen et al. 2009; Schifrin et al. 2015; Litzenburger et al. 2015). However, the conversion of progesterone by CYP260A1 is very unselective (Khatri et al. 2016a, b; Salamanca-Pinzon et al. 2016), yielding a mixture of $1 \alpha$-progesterone, $17 \alpha$-progesterone and other products. Structure-guided rational design was conducted to mutate S326 to an asparagine, resulting in mutant S326R that displayed much better activity and selectivity for the formation of

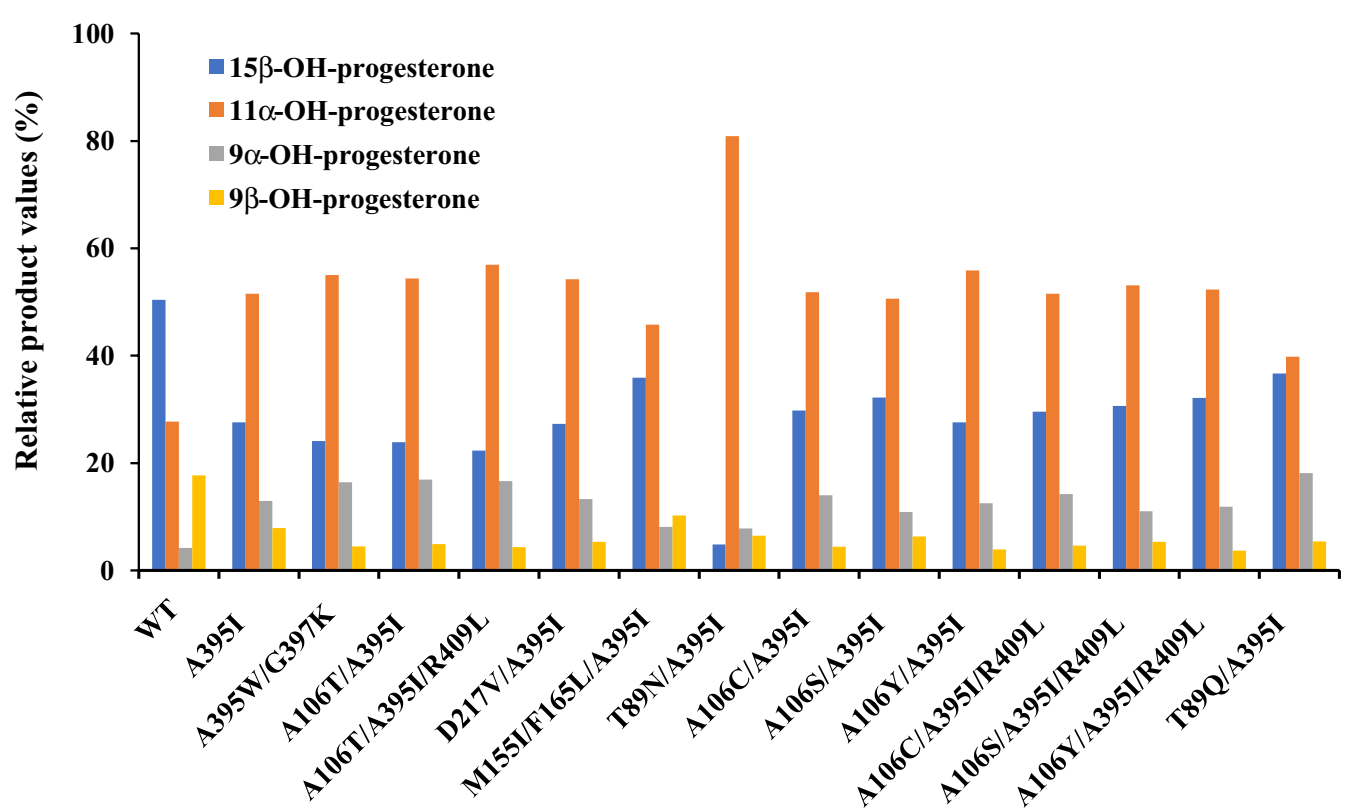

Fig. 9 Best CYP106A2 mutants on progesterone. Relative values [\%] of progesterone substrate and monohydroxylated products (15 $\beta-, 11 \mathrm{a}-$, 9a- and 6B) produced by CYP106A2 WT mutants A395I and G395W/G397K, and best combinatorially derived mutants in $6 \mathrm{~h}$ whole-cell biotransformations with $200 \mu \mathrm{M}$ of progesterone (Nguyen et al. 2012) 
Table 2 Selection of CYP106A2 mutants with different profiles for progesterone hydroxylation

\begin{tabular}{|c|c|c|c|c|c|c|}
\hline Number & Mutation & $15 \beta[\%]$ & $11 \alpha[\%]$ & $9 a[\%]$ & $6 \beta[\%]$ & Progesterone \\
\hline 1 & WT-CYP106A2 & 67.9 & 18.0 & 5.4 & 8.7 & n.d. ${ }^{*}$ \\
\hline 2 & A395T/G397K & 11.2 & 20.0 & 45.1 & 23.7 & n.d.* \\
\hline 3 & A395H/G397Y & 22.9 & 15.2 & 38.6 & 23.3 & n.d.* \\
\hline 4 & A395I & 28.7 & 50.9 & 10.2 & 10.2 & n.d.* \\
\hline 5 & A395E/G397V & 9.4 & 15.9 & 48.6 & 26.1 & n.d.* \\
\hline 6 & A395R/G397K & 9.1 & 12.9 & 44.8 & 33.2 & n.d. ${ }^{*}$ \\
\hline 7 & A395M/G397S & 13.1 & 65.6 & 14.4 & 6.9 & n.d. ${ }^{*}$ \\
\hline 8 & A395R/G397| & 13.2 & 12.7 & 47.0 & 27.2 & n.d. ${ }^{*}$ \\
\hline 9 & A395K & 16.5 & 37.2 & 42.4 & 4.0 & n.d. ${ }^{*}$ \\
\hline 10 & G397W & 27.3 & 36.4 & 27.3 & 9.1 & n.d.* \\
\hline 11 & A395F & 32.5 & 38.3 & 11.5 & 17.7 & n.d. ${ }^{*}$ \\
\hline 12 & A243V & 78.0 & 8.2 & 3.6 & 10.2 & n.d.* \\
\hline 13 & A395W/G397K & 10.5 & 19.2 & 55.9 & 14.3 & n.d. ${ }^{*}$ \\
\hline 14 & A395E/G397Stop & 13.4 & 15.5 & 45.4 & 25.8 & n.d. ${ }^{*}$ \\
\hline 15 & A395S/G397Y & 18.5 & 13.7 & 41.1 & 26.8 & n.d.* \\
\hline 16 & A395R/G397R & 8.8 & 14.9 & 45.8 & 30.6 & n.d.* \\
\hline 17 & D217V/A395E/G397V & 7.5 & 23.2 & 55.9 & 7.9 & 5.4 \\
\hline 18 & F165L/A395E/G397V & 11.3 & 17.2 & 59.7 & 11.0 & 0.9 \\
\hline 19 & A106T/A395R/G397K & 13.0 & 22.4 & 57.4 & 6.8 & 0.4 \\
\hline 20 & A243V/A395R/G397R & 11.8 & 17.6 & 49.7 & 8.3 & 12.7 \\
\hline 21 & A106T/A395R/G397R & 12.9 & 14.9 & 56.2 & 13.3 & 2.7 \\
\hline 22 & F173A & 9.7 & 32.5 & 44.1 & 5.0 & 8.6 \\
\hline 23 & A243S & 3.4 & 4.6 & 2.4 & 82.7 & 6.9 \\
\hline 24 & T247A & 11.7 & 13.1 & 45.7 & 24.3 & 4.3 \\
\hline 25 & A243S/T247A & 14.6 & 13.2 & 48.0 & 20.7 & 20.7 \\
\hline 26 & $\mathrm{~F} 173 \mathrm{~A} / \mathrm{A} 243 \mathrm{~S} / \mathrm{T} 247 \mathrm{~A}$ & 13.6 & 6.5 & 8.7 & 57.2 & 19.1 \\
\hline
\end{tabular}

Relative values in \% of progesterone and its monohydroxylated products $15 \beta-, 11 a-, 9 a-$ and $6 \beta$-hydroxyprogesterone after $24 \mathrm{~h}$ in vivo conversion of $200 \mu \mathrm{M}$ progesterone catalyzed by WT CYP106A2 and mutant proteins thereof. Values show percentages with the sum of the substrate progesterone and all monohydroxylated products set as 100\% (n.d.*: not detectable) (Nikolaus et al. 2017)

$1 \alpha$-hydroxy-11-deoxycorticosterone compared to the WT parent (Khatri et al. 2018).

The application of CYP260A1 for steroid conversion is often hindered because of its poor activity and low selectivity. In order to improve its regio- and stereoselectivity for progesterone transformation, Khatri et al. cloned and expressed truncated protein of CYP260A1 ( $\triangle$ CYP260A1) (Khatri et al. 2018), and the first $50 \mathrm{~N}$-terminal residues were removed based on the alternative predicted gene transcript from the NCBI database (Khatri et al. 2016a, b). Laborious efforts combining rational design and directed evolution were employed to create mutants of $\triangle C Y P 260 A 1$ with improved regioselectivity towards progesterone hydroxylation (Khatri et al. 2018). After recovery of complete activity of $\triangle \mathrm{CYP} 260 \mathrm{~A} 1$, the substrate was docked into $\triangle$ CYP260A1 active site to explore potential hotspot residues. The docking results suggested that three small polar residues (Ser225, Ser275 and Ser276) located at opposite sides of the binding pocket may interact with polar groups of progesterone during catalysis. Accordingly, a SM library based on CAST was created on those three residues by randomizing with NDC codon degeneracy (including 12 amino acid residues: Leu, Ile, Arg, His, Asp, Phe, Asn, Cys, Gly, Tyr, Val and Ser) using $\triangle$ CYP260A 1 as template. Mutants of S225X and S275X were either inactive or maintained the similar catalytic activity with WT, and there were only five positive variants at position S276 (S276N, S276I, S276C, S276L and S276V) displaying an altered product profile relative to the WT $\triangle \mathrm{CYP} 260 \mathrm{~A} 1$. Among them, mutants S276N and S276C displayed increased selectivity for $1 \alpha$-hydroxyprogesterone (57 and 48 vs $36 \%$ of WT), with the former showing lesser formation of side products. In contrast, mutants S276I, S276L and S276V displayed moderately enhanced selectivity for product $17 \alpha$-hydroxyprogesterone compared to the WT enzyme (64, 62 and 58 vs 39\%, respectively) (Fig. 10) 


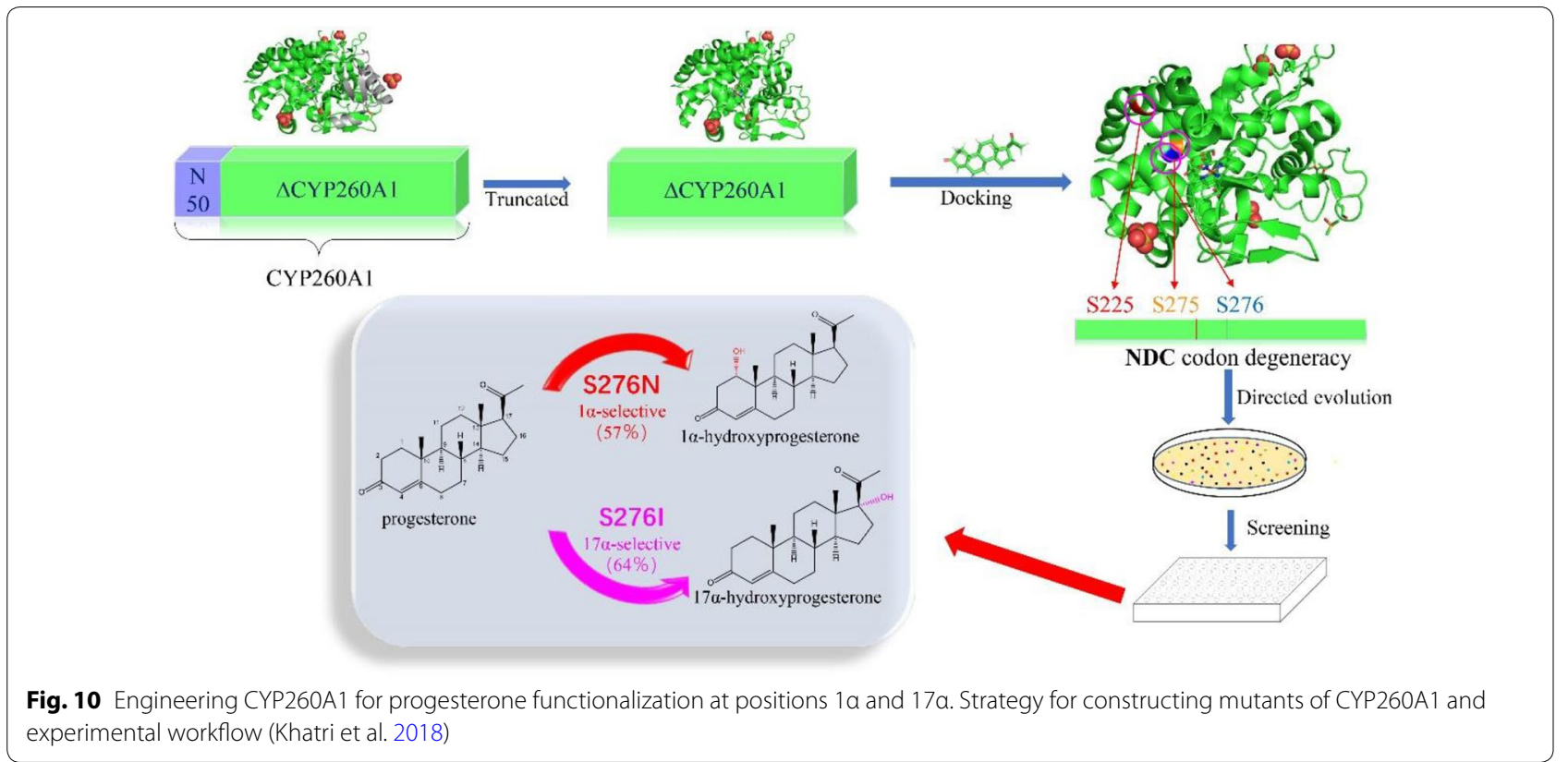

(Khatri et al. 2018). With the addition of position $17 \alpha$ to the above targeted positions, it is clear that directed evolution can generate highly regio- and stereoselective enzymes for challenging biotransformation.

\section{CYP260B1: cytochrome P450 from Sorangium cellulosum}

CYP260B1 is a newly isolated CYP from Sorangium cellulosum with $48 \%$ homology to CYP260A1. Thus far, it has not been well characterized yet (Salamanca-Pinzon et al. 2016). Bernhart and coworkers used CYP260B1 to convert a small substrate library of six $\Delta^{4}$-C21-steroids (progesterone, 17-hydroxyprogesterone, 11-deoxycorticosterone, cortisone, cortisol, and cortodoxone) and five steroidal drugs (dexamethasone, betamethasone, fluorine, budesonide, and desonide) with the adrenal redox partners (Adx and AdR) (Litzenburger and Bernhardt 2017). CYP260B1 showed activity towards most substrates tested except for the steroidal drugs with a fused heterocyclic ring (such as fluorine, budesonide, and desonide), with the highest activity and selectivity achieved for 11-deoxycorticosterone and cortodoxone. For the transformation of 11-deoxycorticosterone, conversion reached almost $100 \%$ and the major product was $9 \alpha-\mathrm{OH}-$ 11 -deoxycorticosterone with $62 \%$ selectivity. In the case of cortodoxone, conversion reached $95 \%$ and the major product was $6 \beta-\mathrm{OH}$-cortodoxone with $94 \%$ selectivity.
The mutant CYP260B1-T224A was created and tested (Litzenburger and Bernhardt 2017), enabling an increase from 62 to $75 \%$ 9 $\alpha$-hydroxy-11-deoxycorticosterone selectivity without activity decline (Fig. 11). The synthetic potential of CYP260B1 remains to be explored.

\section{Conclusions}

In this review, we summarized the achievements attained in the engineering of bacterial CYPs towards steroid hydroxylation during the past decades. Since most WT P450s often suffer from wrong or insufficient enantioand/or regioselectivity, low activity, narrow substrate range, and insufficient thermostability, laboratory evolution and rational design have emerged as promising tools to solve these problems. Relevant examples have been summarized in the synthesis of valuable hydroxylated steroid compounds with different types of bacterial P450s. Notably, while some studies have developed novel directed evolution strategies, others have shown that many P450s still await discovery and characterization. We believe that a combination of both strategies will allow the controlled regio- and stereoselective hydroxylation at any position of interest of a wide range of steroids for the development of more sustainable, efficient and economic biotechnological processes. 


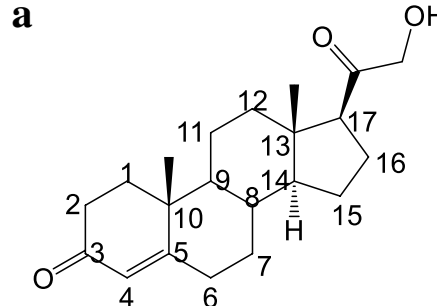

11-Deoxycorticosterone i. CYP260B1 WT Conv. $100 \%$

Sel. $62 \%$

ii. CYP260B1-T224A

Conv. $100 \%$

Sel. $75 \%$

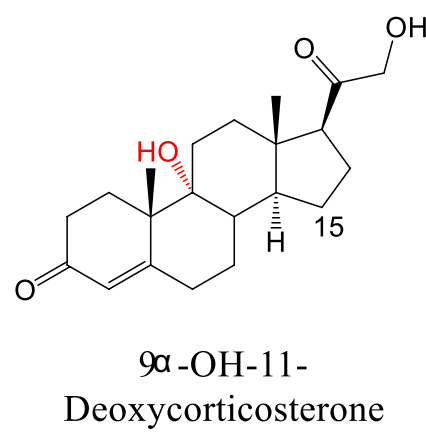

b

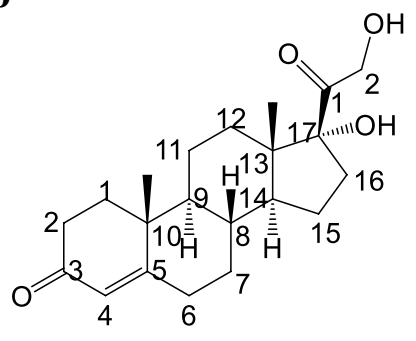

Cortodoxone

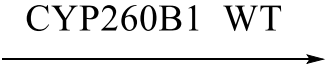

Conv. $95 \%$ Sel. 94\%<smiles>C[C@@]12CCC(=O)C=C1C(O)C[C@@H]1[C@@H]2CC[C@@]2(C)[C@H]1CC[C@@]2(C)C(=O)CO</smiles>

6ß-OH-Cortodoxone

Fig. 11 The conversion and major hydroxylated products of 11-deoxycorticosterone (a) and cortodoxone (b) catalyzed by CYP260B1 and

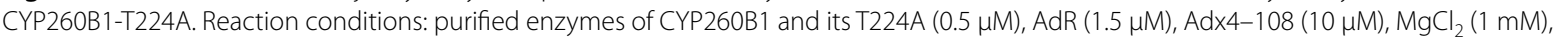
glucose-6-phosphate $(5 \mathrm{mM}$ ) and glucose-6-phosphate dehydrogenase $(1 \mathrm{U})$ in a final volume of $250 \mathrm{\mu l}$ of potassium phosphate buffer $(20 \mathrm{mM}$, pH 7.4) was used. The steroids ( $10 \mathrm{mM}$ stock solution in $\mathrm{EtOH}$ ) were added to a final concentration of $200 \mu \mathrm{M}$. The reactions were initiated by adding $500 \mu \mathrm{M}$ NADPH, $30 \mathrm{~min}, 30^{\circ} \mathrm{C}$

\section{Abbreviations}

CYPs: cytochrome P450 monooxygenases; WT: wild type; FAD: flavin adenine dinucleotide; FMN: flavin mononucleotide; FeS: iron-sulfur cluster; NADH: nicotinamide adenine dinucleotide; NADPH: nicotinamide adenine dinucleotide phosphate; SRS: substrate recognition sites; epPCR: error-prone PCR; SM: saturation mutagenesis; ISM: iterative saturation mutagenesis; CAST: Combinatorial active-site saturation test; MLs: mutability landscapes; MDs: molecular dynamics simulation; Adx: adrenodoxin; AdR: adrenodoxin reductase; PdR: putidaredoxin reductase; Pdx: putidaredoxin.

\section{Acknowledgements}

This work was funded by the National Natural Science Foundation of China (Nos. 21977026 and 21702052) and Research Program of State Key Laboratory of Biocatalysis and Enzyme Engineering.

\section{Authors' contributions}

AL conceived and provided advice in this review. XZ and YP were involved in collecting related material and drafted the manuscript. All authors read and approved the final manuscript.

\section{Funding}

This work was funded by the National Natural Science Foundation of China (Nos. 21977026 and 21702052)

\section{Availability of data and materials}

Not applicable.

\section{Ethics approval and consent to participate}

All the authors have read and agreed the ethics for publishing the manuscript.

\section{Consent for publication}

The authors approved the consent for publishing the manuscript.

\section{Competing interests}

The authors declare that they have no competing interests.

\section{Author details}

1 State Key Laboratory of Biocatalysis and Enzyme Engineering, Hubei Collaborative Innovation Center for Green Transformation of Bio-Resources, Hubei Key Laboratory of Industrial Biotechnology, School of Life Sciences, Hubei University, Wuhan 430062, People's Republic of China. ${ }^{2}$ Biosyntia ApS, 2100 Copenhagen, Denmark.

Received: 15 October 2019 Accepted: 25 December 2019 Published online: 07 January 2020

\section{References}

Acevedo-Rocha CG, Gamble C, Lonsdale R, Li A, Nett N, Hoebenreich S, Deege A (2018) P450-catalyzed regio- and diastereoselective steroid hydroxylation: efficient directed evolution enabled by mutability landscaping. ACS Catal 8(4):3395-3410

Agematu H, Matsumoto N, Fujii Y, Kabumoto H, Doi S, Machia K, Arisawa A (2006) Hydroxylation of testosterone by bacterial cytochromes P450 using the Escherichia coli expression system. Biosci Biotech Bioch 70(1):307-311

Behrendorff JBYH, Gillam EMJ (2016) Prospects for applying synthetic biology to toxicology: future opportunities and current limitations for the repurposing of cytochrome P450 systems. Chem Res Toxicol 30(1):453-468 Behrendorff JB, Huang W, Gillam EM (2015) Directed evolution of cytochrome P450 enzymes for biocatalysis: exploiting the catalytic versatility of enzymes with relaxed substrate specificity. Biochem J 467(1):1-15 
Berg A, Gustafsson J, Ingelman-Sundberg M (1976) Characterization of a cytochrome P-450-dependent steroid hydroxylase system present in Bacillus megaterium. J Biol Chem 251(9):2831-2838

Berg A, Ingelman-Sundberg M, Gustafsson J (1979) Isolation and characterization of cytochrome P-450meg. Acta Biologica et Medica Germanica 38:333-344

Bernhardt R (2008) Molecular evolution of a steroid hydroxylating cytochrome P450 using a versatile steroid detection system for screening. Lipids 43(12):1133-1141

Bernhardt R, Urlacher VB (2014) Cytochromes P450 as promising catalysts for biotechnological application: chances and limitations. Appl microbiol biot 98(14):6185-6203

Bleif S, Hannemann F, Lisurek M, von Kries JP, Zapp J, Dietzen M, Bernhardt $R$ (2011) Identification of CYP106A2 as a regioselective allylic bacterial diterpene hydroxylase. ChemBioChem 12(4):576-582

Bleif S, Hannemann F, Zapp J, Hartmann D, Jauch J, Bernhardt R (2012) A new Bacillus megaterium whole-cell catalyst for the hydroxylation of the pentacyclic triterpene 11-keto- $\beta$-boswellic acid (KBA) based on a recombinant cytochrome $\mathrm{P} 450$ system. Appl Microbiol Biotechnol 93(3):1135-1146

Bracco P, Janssen DB, Schallmey A (2013) Selective steroid oxyfunctionalisation by CYP154C5, a bacterial cytochrome P450. Microb Cell Fact 12(1):95

Coelho PS, Brustad EM, Kannan A, Arnold FH (2013) Olefin cyclopropanation via carbene transfer catalyzed by engineered cytochrome P450 enzymes. Science 339(6117):307-310

Dangi B, Kim KH, Kang SH, Oh TJ (2018) Tracking down a novel steroid hydroxylating promiscuous cytochrome P450, CYP154C8 from Streptomyces sp. W2233-SM. ChemBioChem 19(10):1066-1077

de Vlieger JS, Kolkman AJ, Ampt KA, Commandeur JN, Vermeulen NP, Kool J, Honing M (2010) Determination and identification of estrogenic compounds generated with biosynthetic enzymes using hyphenated screening assays, high resolution mass spectrometry and off-line NMR. J Chromatogr B 878(7-8):667-674

Donova MV (2017) Steroid bioconversions. Methods Mol Biol 1645:1-13

Donova MV, Egorova OV (2012) Microbial steroid transformations: current state and prospects. Appl Microbiol Biotechnol 94(6):1423-1447

Ewen KM, Hannemann F, Khatri Y, Perlova O, Kappl R, Krug D, Bernhardt R (2009) Genome Mining in Sorangium cellulosum So ce56: identification and characterization of the homologous election transfer proteins of a myxobacteria cytochrome P450. J Biol Chem 284(42):28590

Fernandes P, Cruz A, Angelova B, Pinheiro HM, Cabral JMS (2003) Microbial conversion of steroid compounds: recent developments. Enzyme Microb Tech 32(6):688-705

Geronimo I, Denning CA, Rogers WE, Othman T, Huxford T, Heidary DK, Payne CM (2016) Effect of mutation and substrate binding on the stability of cytochrome P450BM3 variants. Biochemistry-US 55(25):3594-3606

Girhard M, Klaus T, Khatri Y, Bernhardt R, Urlacher VB (2010) Characterization of the versatile monooxygenase CYP109B1 from Bacillus subtilis. Appl Microbiol Biot 87(2):595-607

Girvan HM, Munro AW (2016) Applications of microbial cytochrome P450 enzymes in biotechnology and synthetic biology. Curr Opin Chem Biol 31:136-145

Glieder A, Farinas ET, Arnold FH (2002) Laboratory evolution of a soluble, selfsufficient, highly active alkane hydroxylase. Nat Biotechnol 20(11):1135

Gotoh O (1992) Substrate recognition sites in cytochrome P450 family 2 (CYP2) proteins inferred from comparative analyses of amino acid and coding nucleotide sequences. J Biol Chem 267(1):83-90

Guengerich FP (2001) Common and uncommon cytochrome P450 reactions related to metabolism and chemical toxicity. Chem Res Toxico 14(6):611-650

Guengerich FP (2002) Cytochrome P450 enzymes in the generation of commercial products. Nat Rev Drug Discov 1(5):359

Guengerich FP (2003) Cytochrome P450 oxidations in the generation of reactive electrophiles: epoxidation and related reactions. Arch Biochem Biophys 409(1):59-71

Guengerich FP (2008) Cytochrome p450 and chemical toxicology. Chem Res Toxicol 21(1):70-83

Guengerich FP, Waterman MR, Egli M (2016) Recent structural Insights into cytochrome P450 function. Trends Pharmacol Sci 37(8):625-640
Hannemann F, Bernhardt R (2006) Design of an Escherichia coli system for whole cell mediated steroid synthesis and molecular evolution of steroid hydroxylases. J Biotechnol 124(1):172-181

Hartwig JF (2015) Evolution of C-H bond functionalization from methane to methodology. J Am Chem Soc 138(1):2-24

Huang WC, Westlake AC, Maréchal JD, Joyce MG, Moody PC, Roberts GC (2007) Filling a hole in cytochrome P450 BM3 improves substrate binding and catalytic efficiency. J Mol Biol 373(3):633-651

Janocha S, Carius Y, Hutter M, Lancaster CRD, Bernhardt R (2016) Crystal structure of CYP106A2 in substrate-free and substrate-bound form. ChemBioChem 17(9):852-860

Jóźwik IK, Kiss FM, Gricman Ł, Abdulmughni A, Brill E, Zapp J, Thunnissen AMW (2016) Structural basis of steroid binding and oxidation by the cytochrome P450 CYP109E1 from Bacillus megaterium. FEBS J 283:4128-4148

Kellner DG, Maves SA, Sligar SG (1997) Engineering cytochrome P450s for bioremediation. Curr Opin Biotechnol 8(3):274-278

Khatri Y, Ringle M, Lisurek M, von Kries JP, Zapp J, Bernhardt R (2016a) Substrate hunting for the myxobacterial CYP260A1 revealed novel 1a-hydroxylated products from C-19 steroids. ChemBioChem 17(1):90-101

Khatri Y, Carius Y, Ringle M, Lancaster CRD, Bernhardt R (2016b) Structural characterization of CYP260A1 from Sorangium cellulosum to investigate the 1a-hydroxylation of a mineralocorticoid. FEBS Lett 590(24):4638

Khatri Y, Jóźwik IK, Ringle M, lonescu IA, Litzenburger M, Hutter MC, Bernhardt R (2018) Structure-based engineering of steroidogenic CYP260A1 for stereo- and regioselective hydroxylation of progesterone. ACS Chem Biol 13(4):1021-1028

Kille S, Zilly FE, Acevedo JP, Reetz MT (2011) Regio- and stereoselectivity of P450-catalysed hydroxylation of steroids controlled by laboratory evolution. Nat Chem 3(9):738-743

Kiss FM, Lundemo MT, Zapp J, Woodley JM, Bernhardt R (2015a) Process development for the production of $15 \beta$-hydroxycyproterone acetate using Bacillus megaterium expressing CYP106A2 as whole-cell biocatalyst. Microb Cell Fact 14(1):28

Kiss FM, Schmitz D, Zapp J, Dier TK, Volmer DA, Bernhardt R (2015b) Comparison of CYP106A1 and CYP106A2 from Bacillus megaterium-identification of a novel 11-oxidase activity. Appl Microbiol Biot 99:8495-8514

Kumar S, Halpert JR (2005) Use of directed evolution of mammalian cytochromes P450 for investigating the molecular basis of enzyme function and generating novel biocatalysts. Biochem Bioph Res Co 338(1):456-464

Lewis JC, Coelho PS, Arnold FH (2011) Enzymatic functionalization of carbonhydrogen bonds. Chem Soc Rev 40(4):2003-2021

Li Z, van Beilen JB, Duetz WA, Schmid A, de Raadt A, Griengl H, Witholt B (2002) Oxidative biotransformations using oxygenases. Curr Opin Chem Biol 6(2):136-144

Li A, Liu J, Pham SQ, Li Z (2013) Engineered P450pyr monooxygenase for asymmetric epoxidation of alkenes with unique and high enantioselectivity. Chem Commun 49(98):11572

Li A, Wu S, Adams JP, Snajdrona R, Li Z (2015) Asymmetric epoxidation of alkenes and benzylic hydroxylation with P450tol monooxygenase from Rhodococcus coprophilus TC-2. Chem Commun 45(52):8771-8774

Li RJ, Xu JH, Yin YC, Wirth N, Ren JM, Zen BB, Yu HL (2016a) Rapid probing of the reactivity of $\mathrm{P} 450$ monooxygenases from the CYP116B subfamily using a substrate-based method. New J Chem 40:8928-8934

Li A, Ilie A, Sun Z (2016b) Whole-cell-catalyzed multiple regio- and stereoselective functionalizations in cascade reactions enabled by directed evolution. Angew Chem Int Ed 128(39):12205-12208

Li A, Wang B, llie A, Dubey KD, Bange G, Korendovych IV, Reetz MT (2017) A redox-mediated Kemp eliminase. Nat Commun 8:14876

Lisurek M, Kang M, Hartmann R, Bernhardt R (2004) Identification of monohydroxy progesterones produced by CYP106A2 using comparative HPLC and electrospray ionisation collision-induced dissociation mass spectrometry. Biochem Bioph Res Co 319:677-682

Lisurek M, Simgen B, Antes I, Bernhardt R (2008) Theoretical and experimental evaluation of a CYP106A2 low homology model and production of mutants with changed activity and selectivity of hydroxylation. ChemBioChem 9(9):1439-1449

Litzenburger M, Bernhardt R (2017) CYP260B1 acts as 9a-hydroxylase for 11-deoxycorticosterone. Steroids 127:40-45 
Litzenburger M, Kern F, Khatri Y, Bernhardt R (2015) Conversions of tricyclic antidepressants and antipsychotics with selected P450s from Sorangium cellulosum So ce56. Drug Metab Dispos 43(3):392-399

Liu X, Kong JQ (2017) Steroids hydroxylation catalyzed by the monooxygenase mutant 139-3 from Bacillus megaterium BM3. Acta Pharm Sin B 7(4):120-126

Liu X, Wang ZB, Wang YN, Kong JQ (2016) Probing steroidal substrate specificity of cytochrome P450 BM3 variants. Molecules 21(6):760

Lussenburg BM, Babel LC, Vermeulen NP, Commandeur JN (2005) Evaluation of alkoxyresorufins as fluorescent substrates for cytochrome P450 BM3 and site-directed mutants. Anal Biochem 341(1):148-155

Makino T, Katsuyama Y, Otomatsu T, Misawa N, Ohnishi Y (2014) Regio- and stereospecific hydroxylation of various steroids at the 16 a position of the D ring by the Streptomyces griseus cytochrome P450 CYP154C3. Appl Environ Microb 80(4):1371

Mallinson SJB, Machovina MM, Silveira RL, Garcia BM, Gallup N, Johnson CW, Houk KN (2018) A promiscuous cytochrome P450 aromatic O-demethylase for lignin bioconversion. Nat Commun 9(1):2487

Morant M, Bak S, Møller BL, Werck-Reichhart D (2003) Plant cytochromes P450: tools for pharmacology, plant protection and phytoremediation. Curr Opin Biotechnol 14(2):151-162

Munro AW, Girvan HM, Mclean KJ (2007) Variations on a (t)heme-novel mechanisms, redox partners and catalytic functions in the cytochrome P450 superfamily. Nat Prod Rep 24(3):585-609

Narhi LO, Fulco AJ (1986) Characterization of a catalytically self-sufficient 119,000-dalton cytochrome P-450 monooxygenase induced by barbiturates in Bacillus megaterium. J Biol Chem 261(16):7160-7169

Nelson DR (2018) Cytochrome P450 diversity in the tree of life. BBA-Proteins Proteom 1866(1):141-154

Nguyen KT, Günnewich N, Hannemann F, Bernhardt R (2012) Changing the regioselectivity of a $\mathrm{P} 450$ from $\mathrm{C} 15$ to $\mathrm{C} 11$ hydroxylation of progesterone. ChemBioChem 13(8):1161-1166

Nikolaus J, Nguyen KT, Virus C, Riehm JL, Hutter M, Bernhardt R (2017) Engineering of CYP106A2 for steroid $9 a-$ and $6 \beta$-hydroxylation. Steroids 120:41-48

Oliver CF, Modi Sandeep, Sutcliffe Michael J, Primrose WU, Lian LY, Roberts Gordon CK (1997) A single mutation in cytochrome P450 BM3 changes substrate orientation in a catalytic intermediate and the regioselectivity of hydroxylation. Biochemistry-US 36(7):1567-1572

O'Reilly E, Corbett M, Hussain S, Kelly PP, Richardson D, Flitsch SL, Turner NJ (2013) Substrate promiscuity of cytochrome P450 RhF. Catal Sci Technol 3(6):1490-1492

Podust LM, Sherman DH (2012) Diversity of P450 enzymes in the biosynthesis of natural products. Nat Prod Rep 29(10):1251

Prier CK, Zhang RK, Buller AR, Brinkann-Chen S, Arnold FH (2017) Enantioselective, intermolecular benzylic $\mathrm{C}-\mathrm{H}$ amination catalyzed by an engineered iron-heme enzyme. Nat Chem 9(7):629

Qu G, Li A, Sun Z, Acevedo-Rocha CG, Reetz MT (2019) The crucial role of methodology development in directed evolution of selective enzymes. Angew Chem Int Edit. https://doi.org/10.1002/anie.201901491

Rauschenbach R, Isernhagen M, Noeske-Jungblut C, Boidol W, Siewert G (1993) Cloning sequencing and expression of the gene for cytochrome P450meg, the steroid-15ß-monooxygenase from Bacillus megaterium ATCC 13368. Mol Gen Genet 241:170-176

Rea V, Kolkman AJ, Vottero E, Stronks EJ, Ampt KAM, Honing M, Commandeur JNM (2012) Active site substitution A82W improves the regioselectivity of steroid hydroxylation by cytochrome P450 BM3 mutants as rationalized by spin relaxation nuclear magnetic Resonance studies. Biochemistry-US 51(3):750-760

Reetz MT (2004) Controlling the enantioselectivity of enzymes by directed evolution: practical and theoretical ramifications. Proc Natl Acad Sci USA 101(16):5716-5722

Reetz MT (2011) Laboratory evolution of stereoselective enzymes: a prolific source of catalysts for asymmetric reactions. Angew Chem Int Ed 50(1):138-174

Reetz MT, Carballeira JD (2007) Iterative saturation mutagenesis (ISM) for rapid directed evolution of functional enzymes. Nat Protoc 2(4):891-903

Reetz MT, Krebs GPL (2011) Challenges in the directed evolution of stereoselective enzymes for use in organic chemistry. C R Chime 14(9):818
Ren X, Yorke JA, Taylor E, Zhang T, Zhou W, Wong LL (2015) Drug oxidation by cytochrome P450BM3: metabolite synthesis and discovering new P450 reaction types. Chem-Eur J 21(42):15039-15047

Renault H, Bassard JE, Hamberger B, Reichhart DW (2014) Cytochrome P450-mediated metabolic engineering: current progress and future challenges. Curr Opin Plant Biol 19(19C):27-34

Ringle M, Khatri Y, Zapp J, Hannemann F, Bernhardt R (2013) Application of a new versatile electron transfer system for cytochrome; P450-based Escherichia coli whole-cell bioconversions. Appl Microbiol Biotechnol 97(17):7741-7754

Roiban GD, Reetz MT (2014) Expanding the toolbox of organic chemists: directed evolution of P450 monooxygenases as catalysts in regio- and stereoselective oxidative hydroxylation. Chem Commun 46(16):2208-2224

Romdhane IB, Frikha F, Maalej-Achouri I, Gargouri A, Belghith H (2012) Gene cloning and molecular characterization of the Talaromyces thermophilus lipase catalyzed efficient hydrolysis and synthesis of esters. Gene 494(1):112-118

Saab-Rincon G, Alwaseem H, Guzmán-Luna V, Olvera L, Fasan R (2017) Stabilization of the reductase domain in the catalytically self-sufficient cytochrome P450BM3 via consensus-guided mutagenesis. ChemBioChem 19(6):622-632

Salamanca-Pinzon SG, Khatri Y, Carius Y, Keller L, Müller R, Lancaster CRD, Bernhardt R (2016) Structure-function analysis for the hydroxylation of $\triangle 4$ C21-steroids by the myxobacterial CYP260B1. FEBS Lett 590(12):1838-1851

Schifrin A, Litzenburger M, Ringle M, Ly TT, Bernhardt R (2015) New sesquiterpene oxidations with CYP260A1 and CYP264B1 from Sorangium cellulosum So ce56. ChemBioChem 16(18):2624-2632

Schmitz D, Janocha S, Kiss FM, Bernhardt R (2018) CYP106A2-a versatile biocatalyst with high potential for biotechnological production of selectively hydroxylated steroid and terpenoid compounds. BBA-Proteins Proteom 1866(1):11-22

Schmitz D, Zapp J, Bernhardt R (2012) Hydroxylation of the triterpenoid dipterocarpol with CYP106A2 from Bacillus megaterium. FEBS J 279(9):1663-1674

Szaleniec M, Wojtkiewicz AM, Bernhardt R, Borowski T, Donova M (2018) Bacterial steroid hydroxylases: enzyme classes, their functions and comparison of their catalytic mechanisms. Appl Microbiol Biol 102(19):8153-8171

Tokuriki N, Jackson CJ, Afriat-Jurnou L, Wyganowski KT, Tang R, Tawfik DS (2012) Diminishing returns and tradeoffs constrain the laboratory optimization of an enzyme. Nat Commun 3:1257

Urlacher VB, Girhard M (2012) Cytochrome p450 monooxygenases: an update on perspectives for synthetic application. Trends Biotechnol 30(1):26-36

Urlacher VB, Marco G (2019) Cytochrome p450 monooxygenases in biotechnology and synthetic biology. Trends Biotechnol 37(8):882-897

van Vugt-Lussenburg BM, Damsten MC, Maasdijk DM, Vermeulen NP, Commandeur JN (2006) Heterotropic and homotropic cooperativity by a drug-metabolising mutant of cytochrome P450 BM3. Biochem Bioph Res Co 346(3):810-818

Venkataraman H, de Beer SB, van Bergen LA, van Essen N, Geerke DP, Vermeulen NP, Commandeur JN (2012) A single active site mutation inverts stereoselectivity of 16-hydroxylation of testosterone catalyzed by engineered cytochrome P450 BM3. ChemBioChem 13(4):520-523

Virus C, Lisurek M, Simgen B, Hannemann F, Bernhardt R (2006) Function and engineering of the 15beta-hydroxylase CYP106A2. Biochem Soc Trans 34:1215-1218

Vottero E, Rea V, Lastdrager J, Honing M, Vermeulen NP, Commandeor JN (2011) Role of residue 87 in substrate selectivity and regioselectivity of drug-metabolizing cytochrome P450 CYP102A1 M11. J Biol Inorg Chem 16(6):899-912

Wang ZJ, Peck NE, Renata H, Arnold FH (2014) Cytochrome P450-catalyzed insertion of carbenoids into N-H bonds. Chem Sci 5:598-601

Whitehouse CJ, Bell SG, Tufton HG, Kenny RJ, Ogilvie LC, Wong LL (2008) Evolved CYP102A1 (P450 BM3) variants oxidise a range of non-natural substrates and offer new selectivity options. Chem Commun 8:966-968

Whitehouse CJ, Bell SG, Yang W, Yorke JA, Blanford CF, Strong AJ, Wong LL (2009) A highly active single-mutation variant of P450BM3 (CYP102A1). ChemBioChem 10(10):1654-1656 
Zhang RK, Huang X, Arnold FH (2019) Selective CH bond functionalization with engineered heme proteins: new tools to generate complexity. Cur Opin Chem Biol 49:67-75

Zhou H, Wang B, Wang F, Yu X, Ma L, Li A, Reetz MT (2019) Chemo-and regioselective dihydroxylation of benzene to hydroquinone enabled by engineered cytochrome P450 monooxygenase. Angew Chem Int Ed 131(3):774-778

\section{Publisher's Note}

Springer Nature remains neutral with regard to jurisdictional claims in published maps and institutional affiliations.

\section{Submit your manuscript to a SpringerOpen ${ }^{\odot}$ journal and benefit from:}

- Convenient online submission

- Rigorous peer review

- Open access: articles freely available online

- High visibility within the field

- Retaining the copyright to your article

Submit your next manuscript at $\boldsymbol{\nabla}$ springeropen.com 